\title{
Sex Differences in Tolerance to Delta-9-Tetrahydrocannabinol in Mice With Cisplatin-Evoked Chronic Neuropathic Pain
}

\author{
Angela N. Henderson-Redmond ${ }^{1,2,3 *}$, LaTaijah C. Crawford ${ }^{1,3}$, Diana E. Sepulveda ${ }^{2,3}$, \\ David E. Hale ${ }^{3}$, Julia J. Lesperance ${ }^{3}$ and Daniel J. Morgan ${ }^{1,2,3,4}$
}

${ }^{1}$ Department of Biomedical Sciences, Marshall University, Huntington, WV, United States, ${ }^{2}$ Department of Pharmacology, Penn State University College of Medicine, Hershey, PA, United States, ${ }^{3}$ Department of Anesthesiology and Perioperative Medicine, Penn State University College of Medicine, Hershey, PA, United States, ${ }^{4}$ Department of Neural and Behavioral Sciences, Penn State University College of Medicine, Hershey, PA, United States

OPEN ACCESS

Edited by:

Olga Kovalchuk,

University of Lethbridge, Canada

Reviewed by:

Shajer Manzoor,

University of Alabama at Birmingham, United States

Ninjit Dhanota,

Weill Cornell Medicine, United States

Sara Jane Ward,

Temple University, United States

*Correspondence:

Angela N. Henderson-Redmond redmonda@marshall.edu

Specialty section:

This article was submitted to

Molecular Diagnostics and

Therapeutics,

a section of the journal

Frontiers in Molecular Biosciences

Received: 22 March 2021 Accepted: 02 June 2021

Published: 25 June 2021

Citation:

Henderson-Redmond AN,

Crawford LC, Sepulveda DE, Hale DE, Lesperance JJ and Morgan DJ (2021) Sex Differences in Tolerance to Delta9-Tetrahydrocannabinol in Mice With Cisplatin-Evoked Chronic Neuropathic Pain.

Front. Mol. Biosci. 8:684115. doi: 10.3389/fmolb.2021.684115
Tolerance to the pain-relieving effects of cannabinoids limits the therapeutic potential of these drugs in patients with chronic pain. Recent preclinical research with rodents and clinical studies in humans has suggested important differences between males and females in the development of tolerance to cannabinoids. Our previous work found that male mice expressing a desensitization resistant form (S426A/S430A) of the type 1 cannabinoid receptor $\left(\mathrm{CB}_{1} \mathrm{R}\right)$ show delayed tolerance and increased sensitivity to the antinociceptive effects of delta-9-tetrahydrocannabinol $\left(\Delta^{9}-\mathrm{THC}\right)$. Sex differences in tolerance have been reported in rodent models with females acquiring tolerance to $\Delta^{9}$ THC faster than males. However, it remains unknown whether the S426A/S430A mutation alters analgesic tolerance to $\Delta^{9}-\mathrm{THC}$ in mice with chemotherapy-evoked chronic neuropathic pain, and also whether this tolerance might be different between males and females. Male and female S426A/S430A mutant and wild-type littermates were made neuropathic using four once-weekly injections of $5 \mathrm{mg} / \mathrm{kg}$ cisplatin and subsequently assessed for tolerance to the anti-allodynic effects of 6 and $/ o r ~ 10 \mathrm{mg} / \mathrm{kg} \Delta^{9}-\mathrm{THC}$. Females acquired tolerance to the anti-allodynic effects of both 6 and $10 \mathrm{mg} / \mathrm{kg} \Delta^{9}$-THC faster than males. In contrast, the S426A/S430A mutation did not alter tolerance to $\Delta^{9}$-THC in either male or female mice. The anti-allodynic effects of $\Delta^{9}$-THC were blocked following pretreatment with the $\mathrm{CB}_{1} \mathrm{R}$ antagonist, rimonabant, and partially blocked following pretreatment with the $\mathrm{CB}_{2} \mathrm{R}$ inverse agonist, SR144528. Our results show that disruption of the GRK/ $\beta$-arrestin-2 pathway of desensitization did not affect sensitivity and/or tolerance to $\Delta^{9}$-THC in a chronic pain model of neuropathy.

Keywords: sex-differences, chronic pain, tolerance, cisplatin, mice, tetrahydrocannabinol, cannabinoids

\footnotetext{
Abbreviations: ANOVA, analysis of variance; $\mathrm{CB}$, cannabinoid; $\mathrm{CB}_{1} / \mathrm{CB}_{1} \mathrm{R}$, type-1 cannabinoid receptor; $\mathrm{CB}_{2} / \mathrm{CB}_{2} \mathrm{R}$, type-2 cannabinoid receptor; $\mathrm{CBD}$, cannabidiol; CENP, chemotherapy-evoked neuropathic pain; CUD, cannabinoid use disorder(s); $\Delta^{9}$-THC: delta-9-tetrahydrocannabinol; GPCR, G protein-coupled receptor; GRK, G protein-coupled receptor kinase; IP, intraperitoneal; KI, knock-in; MS, multiple sclerosis; NRS-PI, numerical rating scale for pain intensity; SC, subcutaneous; SEM, standard error of the mean; WT, wild-type.
} 


\section{INTRODUCTION}

Chemotherapy-evoked neuropathic pain (CENP) is a doselimiting adverse effect occurring in up to $90 \%$ of individuals receiving neurotoxic chemotherapy (Fallon and Colvin, 2013), including the platinum-based cisplatin (Roelofs et al., 1984; Van Der Hoop et al., 1990). As cisplatin does not cross the bloodbrain barrier, cisplatin primarily damages peripheral tissuesincluding dorsal root ganglia and sensory fibers (Gregg et al., 1992), resulting in the development of peripheral neuropathy. Common symptoms of sensory neuropathy include numbness, tingling, and burning pain typically originating in the feet. While sensory neuropathies may spontaneously resolve over time in some patients, in others, it becomes chronic. While treatment options for CENP range from anticonvulsants, antidepressants, and topical treatment, including lidocaine and capsaicin, opioids remain the treatment gold standard (for a review, see Fallon and Colvin, 2013). However, opioids display limited efficacy in the context of neuropathic pain (Arnér and Meyerson, 1988; Dellemijn, 1999) while retaining significant abuse liability.

Cannabinoids represent a viable alternative to opioids for chronic, neuropathic pain management. The endocannabinoid system plays an important role in pain modulation (for a review, see Walker et al., 2001) and cannabinoid (CB) drugs can induce analgesia through activation of two $\mathrm{CB}$ receptors, the cannabinoid type-1 $\left(\mathrm{CB}_{1}\right.$; Matsuda et al., 1990) and the cannabinoid type-2 $\left(\mathrm{CB}_{2}\right.$; Munro et al., 1993) receptors. $\mathrm{CB}_{1}$ receptors are expressed throughout the central nervous system while $\mathrm{CB}_{2}$ receptors are expressed mostly in immune cells (Pertwee, 1997). Rodent models of cisplatin-evoked neuropathy demonstrate cisplatin-mediated increases in mechanical hyperalgesia and allodynia (Joseph and Levine, 2003) and decreased peripheral nerve conduction (Authier et al., 2003). Systemic administration of endocannabinoids [anandamide; (Khasabova et al., 2012)], select $\mathrm{CB}_{1}$ [ACEA (Vera et al., 2013)] and $\mathrm{CB}_{2}$ [JWH133 (Vera et al., 2013); AM1710 (Deng et al., 2012)]; and mixed $\mathrm{CB}_{1} / \mathrm{CB}_{2}$ agonists [WIN55,212-2 (Vera et al., 2013; Nealon et al., 2019) and CP55,940 (Henderson-Redmond et al., 2020)] have all been shown to attenuate cisplatin-induced mechanical allodynia preclinically. Interestingly, while both cannabidiol (CBD) and $\Delta^{9}$-tetrahydrocannabinol $\left(\Delta^{9}\right.$-THC), were able to attenuate mechanical allodynia in paclitaxel-treated mice, CBD (but not $\Delta^{9}$-THC) was able to attenuate mechanical allodynia in oxaliplatin-treated mice while $\Delta^{9}$-THC (but not CBD) attenuated mechanical allodynia in vincristine-treated mice (King et al., 2017). Taken together, these findings suggest a role for cannabinoids in mediating CENP.

Tolerance to $\Delta^{9}$-THC, a mixed $\mathrm{CB}_{1} / \mathrm{CB}_{2}$ agonist, has been demonstrated in humans (Jones et al., 1981; Haney et al., 1999; D'Souza et al., 2008; Gorelick et al., 2012; Cuttler et al., 2016) and pre-clinical rodent models (Bass and Martin, 2000; Morgan et al., 2014; Wakley et al., 2014b; Nealon et al., 2019; Henderson-Redmond et al., 2020; Wiley et al., 2021). Previous work has shown that desensitization of the $\mathrm{CB}_{1}$ receptor represents one potential neuroadaptation that can mediate tolerance to cannabinoids (Jin et al., 1999; Martin et al., 2004; Selley et al., 2004; Daigle et al., 2008; Nguyen et al., 2012). $\mathrm{CB}_{1}$ receptor-mediated desensitization occurs via phosphorylation by a $G$ protein-coupled receptor kinase (GRK) and consequent recruitment of $\beta$-arrestin-2 (Sim et al., 1996; Nguyen et al., 2012). Ensuing studies determined that mutating two serine residues (S426 and S430) to alanines in the carboxy terminus of the $C_{1}$ receptor tail prevented $\mathrm{CB}_{1}$ receptor desensitization in vitro (Jin et al., 1999; Daigle et al., 2008). Subsequent in vivo studies revealed that male mice expressing the S426A/S430A mutations were more sensitive to and displayed slower tolerance to the antinociceptive effects of $\Delta^{9}$-THC in acute models of thermal (tail-flick; Morgan et al., 2014; HendersonRedmond et al., 2020) and inflammatory (formalin; LaFleur et al., 2018) pain. However, it remains unknown whether these mutations, which disrupt GRK/ $\beta$-arrestin-2 desensitization of the $\mathrm{CB}_{1}$ receptor, likewise mediate tolerance to $\Delta^{9}$-THC in a chemotherapy-evoked model of chronic, neuropathic pain.

Women have a higher prevalence of developing neuropathic pain compared to men (Rosen et al., 2017; Fillingim et al., 2009; Mogil, 2012). In addition, more females than males report using $\Delta^{9}$-THC for medical purposes (Cuttler et al., 2016). Although a greater number of men present with cannabinoid use disorders (CUDs; Hernandez-Avila et al., 2004; Khan et al., 2013), women tend to show a more rapid progression from first use to dependence, an effect termed "telescoping" (Hernandez-Avila et al., 2004; Ehlers et al., 2010). Sex has been shown to modulate the rate of tolerance to the acute antinociceptive effects of $\Delta^{9}$ THC in the tail-flick assay, with female rodents displaying more rapid tolerance than their male littermates (Wakley et al., 2014b). Therefore, it is imperative to identify sex differences that influence both efficacy and tolerance for the effects of $\Delta^{9}$ THC in chronic, neuropathic pain. Previously, we have shown that disruption of GRK/ $\beta$-arrestin-2-induced desensitization of $\mathrm{CB}_{1}$ receptors using S426A/S430A mutant mice delays tolerance to the effects of $\Delta^{9}$-THC in acute and inflammatory pain. The goal of the current study was to determine whether tolerance was also delayed for the effects of $\Delta^{9}$-THC in these mutant mice for cisplatin-evoked neuropathic pain, and whether the mechanisms of cannabinoid tolerance might be sex-specific.

\section{MATERIALS AND METHODS}

\section{Subjects}

Subjects included 159 experimentally naïve age-matched (10-16 weeks; $20-35 \mathrm{~g})$ adult male $(N=72)$ and female $(N=$ 87) S426A/S430A mutant $(\mathrm{KI} ; N=27)$ and wild-type (WT; $N=$ 132) mice backcrossed for $10^{+}$generations onto a $\mathrm{C} 57 \mathrm{BL} / 6 \mathrm{~J}$ background. Desensitization-resistant S426A/S430A mice were created as previously described by replacing serines 426 and 430 with alanines in the carboxy terminal of the $\mathrm{CB}_{1}$ receptor (Morgan et al., 2014). Mice were group housed (3-5/cage) during all studies and kept on a 12:12 h light/dark cycle (lights out at 18:00) with ad libitum access to food and 
water. Female mice, while group housed, were not monitored for estrus cycle. Mice were weighed daily prior to drug administration to ensure proper dosing. Animal care procedures were conducted in accordance with $\mathrm{NIH}$ guidelines for the Humane Care and Use of Laboratory Animals (2015) and with approval from the Pennsylvania State University and Marshall University Institutional Animal Care and Use Committees (IACUC).

\section{Drugs/Materials}

Delta-9-tetrahydrocannabinol $\left(\Delta^{9}\right.$-THC) was obtained from the National Institute on Drug Abuse Drug Supply Program (Bethesda, $\mathrm{MD}$, United States). The selective $\mathrm{CB}_{1}$ receptor inverse agonist rimonabant (SR141716; Rinaldi-Carmona et al., 1994), and the $\mathrm{CB}_{2}$ receptor-selective inverse agonist, SR144528 (Rinaldi-Carmona et al., 1998), were obtained from the Cayman Chemical Company (Ann Arbor, MI, United States). For all experiments, $\Delta^{9}$-THC, rimonabant, and SR144528 were dissolved in $0.9 \%$ saline, 5\% Cremaphor $\mathrm{EL}$, and $5 \%$ ethanol (18:1:1 v/v/v) and administered intraperitoneally (IP) using an injection volume of $10 \mathrm{ml} / \mathrm{kg}$. Drug injections were given either 30 or $60 \mathrm{~min}$ (see below) prior to testing. Cisplatin was obtained from Tocris (Minneapolis, $\mathrm{MN}$, United States), dissolved in $0.9 \%$ physiological saline, and administered IP immediately following subcutaneous (SC) administration of $1 \mathrm{ml}$ of $4 \%$ sodium bicarbonate (Fisher Scientific, Pittsburgh, PA, United States) solution dissolved in $0.9 \%$ saline. The selection of $\Delta^{9}$-THC, rimonabant, and SR144528 doses were based on prior work in our lab (Yuill et al., 2017; Henderson-Redmond et al., 2020).

\section{Cisplatin-Induced Neuropathy and Von Frey Testing}

Neuropathic pain was induced in male $(N=72)$ and female $(N=$ 87) S426A/S430A and wild-type littermates with four weeks of once-weekly injections of $5 \mathrm{mg} / \mathrm{kg}$ cisplatin (IP). To prevent renal damage and lethality from cisplatin due to nephrotoxicity, mice were co-administered $1 \mathrm{ml}$ of a $4 \%$ sodium bicarbonate solution (SC) prior to treatment with cisplatin (Guindon et al., 2014). To confirm the establishment of a neuropathic pain state, mechanical allodynia was assessed prior to and after cisplatin treatment using an electronic von Frey anesthesiometer equipped with a semiflexible polypropylene super-tip (IITC Life Science Inc., Woodland Hills, CA, United States).

Mice were acclimated in small acrylic chambers $\left(2.5^{\prime \prime} \times 4^{\prime \prime} \times\right.$ $3.5^{\prime \prime}$ ) on a wire mesh table for 20 min prior to von Frey testing. Mechanical allodynia was assessed by measuring the amount of force (in grams) applied to the right hind paw that was required to elicit a paw withdrawal response. Measurements were made in triplicate with an interval of $\sim 3-5$ min between testing trials and the average value was calculated. Pre- and post-baseline measurements of mechanical allodynia were assessed prior to and after cisplatin treatment. Mice that did not exhibit at least a $40 \%$ reduction in pre-vs. post-baseline measurements of mechanical allodynia after the last cisplatin treatment were considered non-neuropathic and excluded from the study
( $\sim \%$ of mice). Neuropathic mice were injected (IP) once-daily with either vehicle (18:1:1), $6 \mathrm{mg} / \mathrm{kg}$, or $10 \mathrm{mg} / \mathrm{kg} \Delta^{9}$-THC $60 \mathrm{~min}$ prior to von Frey testing. For dose response testing, female wildtype mice were injected once-daily and assessed for mechanical allodynia $60 \mathrm{~min}$ following treatment with vehicle $(0 ; 18: 1: 1$; day 1 ), $0.3 \mathrm{mg} / \mathrm{kg}$ (day 1 ), $1 \mathrm{mg} / \mathrm{kg}$ (day 2), $3 \mathrm{mg} / \mathrm{kg}$ (day 3 ), $10 \mathrm{mg} / \mathrm{kg}$ (day 4 ), and $30 \mathrm{mg} / \mathrm{kg}$ (day 5) of $\Delta^{9}$-THC to determine the $\Delta^{9}$ THC dose that could fully reverse cisplatin-induced allodynia.

\section{Use of $\mathrm{CB}_{\mathbf{1}}$ and $\mathrm{CB}_{\mathbf{2}}$ Receptor Antagonists}

Since $\Delta^{9}-\mathrm{THC}$ is a mixed cannabinoid agonist at both $\mathrm{CB}_{1}$ and $\mathrm{CB}_{2}$ receptors, the goal of this experiment was to determine the extent to which the anti-allodynic effects of $\Delta^{9}$-THC were mediated by each of those receptors. This was accomplished with a separate group of neuropathic male $(N=16)$ and female $(N=16)$ wild-type mice, assessed using a within-subjects design, to determine the effects of Vehicle (18:1:1; Veh), $10 \mathrm{mg} / \mathrm{kg}$ rimonabant (SR141716; $\mathrm{CB}_{1} \mathrm{~A}$ inverse agonist), and $10 \mathrm{mg} / \mathrm{kg} \mathrm{SR} 144528\left(\mathrm{CB}_{2}\right.$ inverse agonist; $\left.\mathrm{CB}_{2} \mathrm{~A}\right)$ alone or in combination with $10 \mathrm{mg} / \mathrm{kg} \Delta^{9}$-THC. The dose of $10 \mathrm{mg} / \mathrm{kg} \Delta^{9}$-THC was chosen because it fully reversed mechanical allodynia in both male and female mice. Mice were treated once-weekly (Wednesdays) with one of the following six IP injection combinations (Veh/Veh; $\mathrm{CB}_{1} \mathrm{~A} /$ Veh; $\mathrm{CB}_{2} \mathrm{~A} / \mathrm{Veh}$; Veh $/ \Delta^{9}-\mathrm{THC} ; \mathrm{CB}_{1} \mathrm{~A} / \Delta^{9}-\mathrm{THC}$; or $\mathrm{CB}_{2} \mathrm{~A} / \Delta^{9}$ THC. All mice were randomly assigned to treatment order. On testing days, mice were first treated (IP) with either: Vehicle, $10 \mathrm{mg} / \mathrm{kg} \mathrm{CB}_{1} \mathrm{~A}$, or $10 \mathrm{mg} / \mathrm{kg} \quad \mathrm{CB}_{2} \mathrm{~A}$ and assessed for mechanical allodynia $30 \mathrm{~min}$ later. Immediately after this assessment, mice were then injected (IP) with either vehicle or $10 \mathrm{mg} / \mathrm{kg} \Delta^{9}$-THC and reassessed for mechanical allodynia with the von Frey test 60 min later. All results were reported as the amount of force (in grams) required to elicit a pawwithdrawal response.

\section{Data Analyses}

Data were analyzed using SPSS version 25.0 (IBM SPSS Statistics, Armonk, NY, United States) and Prism Graph Pad (7.05; GraphPad, La Jolla, CA, United States). Although female mice were used, vaginal smears were not performed to assess estrus cycle stage. The investigator performing the experiment was blinded to mouse genotypes and drug treatment. Two- and three-way analysis of variance (ANOVAs) analyses were run where appropriate with genotype, day/dose, sex, and/or time point as the main factors. Since we were specifically interested in examining whether there were differences in genotype as a function of sex, we followed up three-way ANOVAs with two-way ANOVAs for tolerance experiments. For all repeated measure analyses, Mauchly's test of sphericity was calculated to assess equal variance. Where sphericity was violated, the Greenhouse-Geisser correction was used to reduce the probability of making a type I error. When the Greenhouse-Geisser correction was used for reporting degrees of freedom, it has been rounded off to the nearest whole number. Bonferroni post-hoc analyses were performed when significant interaction effects were detected. All data 

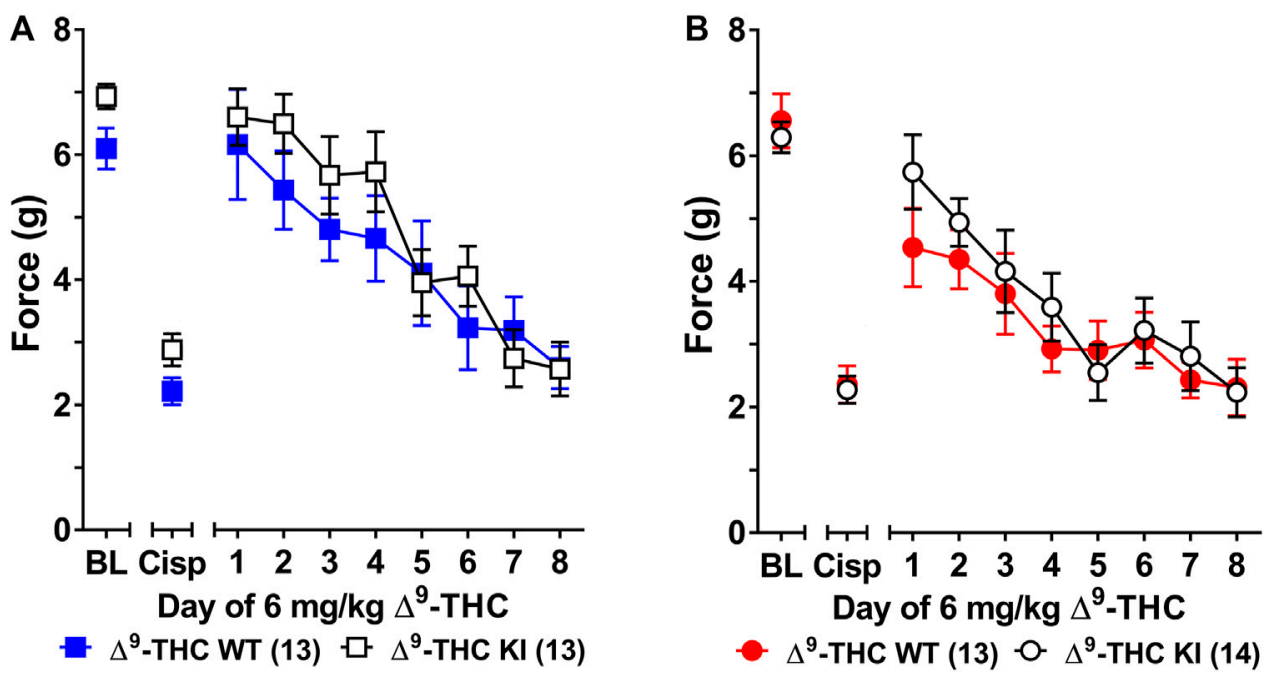

FIGURE 1 | Development of tolerance to the anti-allodynic effects of $6 \mathrm{mg} / \mathrm{kg}$ of $\Delta^{9}$-THC in male and female wild-type and S426A/S430A mice. Tolerance to the anti-allodynic effects of $6 \mathrm{mg} / \mathrm{kg} \Delta^{9}$-THC was determined in both male (A) and female (B) S426A/S430A (KI; unfilled) and wild-type (WT; filled) mice. Mice were assessed via the von Frey assay for the amount of force (in grams) required to elicit a paw withdrawal response 60 min following treatment with $6 \mathrm{mg} / \mathrm{kg} \Delta^{9}$-THC. BL represents the pre-cisplatin baseline and CISP the post-cisplatin baseline. Error bars represent the mean \pm SEM. Each mouse was tested in triplicate and those values averaged to determine a single value for each mouse each day of testing. Data were analyzed using separate two-way ANOVAs with Bonferroni post-hoc tests. Sample sizes for each group (shown in parentheses) include 26 male (13 WT; $13 \mathrm{KI})$ and 27 female (13 WT; $14 \mathrm{KI})$ mice.

are expressed as the mean \pm the standard error of the mean (SEM). For all analyses, significance was set at $p<0.05$.

\section{RESULTS}

\section{Tolerance to $6 \mathrm{mg} / \mathrm{kg}$ Delta-9-Tetrahydrocannabinol in Male and Female S426A/S430A and Wild-Type Mice}

Tolerance to the anti-allodynic effects of once-daily injections of $6 \mathrm{mg} / \mathrm{kg} \Delta^{9}$-THC was assessed in male and female S426A/S430A and wild-type mice (Figure 1). Three-way ANOVA (genotype $\mathrm{x}$ sex $x$ treatment) indicated that there was a main effect of cisplatin treatment $\left(F_{1,61}=861.6, p<0.001\right)$ indicating that once-weekly treatment with $5 \mathrm{mg} / \mathrm{kg}$ of cisplatin caused mechanical allodynia associated with chronic neuropathic pain. However, there were no sex $(p=0.54)$ or genotype $(p=0.25)$ differences in either precisplatin $(6.40 \pm 0.15)$ or post-cisplatin $(2.41 \pm 0.12)$ measures of mechanical allodynia.

Three-way ANOVA (sex $\mathrm{x}$ genotype $\mathrm{x}$ day) was performed to assess tolerance to the anti-allodynic effects of once-daily treatment with $6 \mathrm{mg} / \mathrm{kg}$ of $\Delta^{9}$-THC in male and female S426A/S430A and wild-type mice with cisplatin-induced neuropathy (Figure 1). Although all mice developed tolerance to the anti-allodynic effects of $\Delta^{9}$-THC following 8 days of daily treatment $\left(F_{7,336}=40.91, p<0.001\right)$, there was no effect of genotype ( $p=0.423$; Figures 1A,B). There was a main effect of $\operatorname{sex}\left(F_{1,48}=5.035, p=0.029\right)$ indicating that males $(4.44 \pm 0.31)$ showed a greater anti-allodynic response to $6 \mathrm{mg} / \mathrm{kg} \Delta^{9}$-THC than female littermates $(3.47 \pm 0.30)$. There was also a day-by-sex interaction $\left(F_{7,336}=2.250, p=0.030\right)$ such that male mice were more sensitive than female mice to the anti-allodynic effects of $\Delta^{9}$-THC on days $2(p=0.014), 4(p=0.003)$, and $5(p=0.043)$. Comparing males and females to their own baselines, females developed complete tolerance by day 4 and males by day 7 of treatment with $6 \mathrm{mg} / \mathrm{kg} \Delta^{9}$-THC (Figure 2). Taken together, these finding suggest that female mice were faster to develop tolerance to the anti-allodynic effects of $6 \mathrm{mg} / \mathrm{kg} \Delta^{9}$-THC than their male counterparts (Figure 2).

Subsequent one-way ANOVAs for male and female wild-type mice indicated that $6 \mathrm{mg} / \mathrm{kg} \Delta^{9}$-THC caused a complete reversal of neuropathic pain on day 1 in males $(6.25 \pm 0.24, p=1.00)$, with tolerance developing following 5 days of treatment. In contrast, mechanical allodynia associated with neuropathic pain was only partially reversed by $6 \mathrm{mg} / \mathrm{kg} \Delta^{9}$-THC in females on day $1(5.14 \pm$ $0.43, p<0.05$ compared to pre-cisplatin baseline) and they were completely tolerant to the anti-allodynic effects of $6 \mathrm{mg} / \mathrm{kg}$ of $\Delta^{9}$ THC following 4 days of treatment.

The choice to use $6 \mathrm{mg} / \mathrm{kg}$ of $\Delta^{9}$-THC was based on our previous finding that this dose was sufficient to fully reverse cisplatin-evoked mechanical allodynia in male mice (HendersonRedmond et al., 2020). However, since this dose did not fully reverse mechanical allodynia in female mice, a dose-response curve generated in females (Figure 3 insert) revealed that female mice displayed a complete reversal of cisplatin-induced mechanical allodynia when treated with $10 \mathrm{mg} / \mathrm{kg}$ of $\Delta^{9}$-THC. As such, female wild-type and S426A/S430A mice were reassessed for differences in tolerance to $10 \mathrm{mg} / \mathrm{kg} \Delta^{9}$-THC as a function of genotype. Results from a two-way ANOVA assessing tolerance to $10 \mathrm{mg} / \mathrm{kg} \Delta^{9}$-THC in female S426A/ S430A mutant and wild-type mice revealed a main effect of day $\left(F_{7,175}=39.69, p<0.001\right)$, but neither a main effect of genotype $(p=0.8306)$ nor a genotype-by-day interaction $(p=$ 


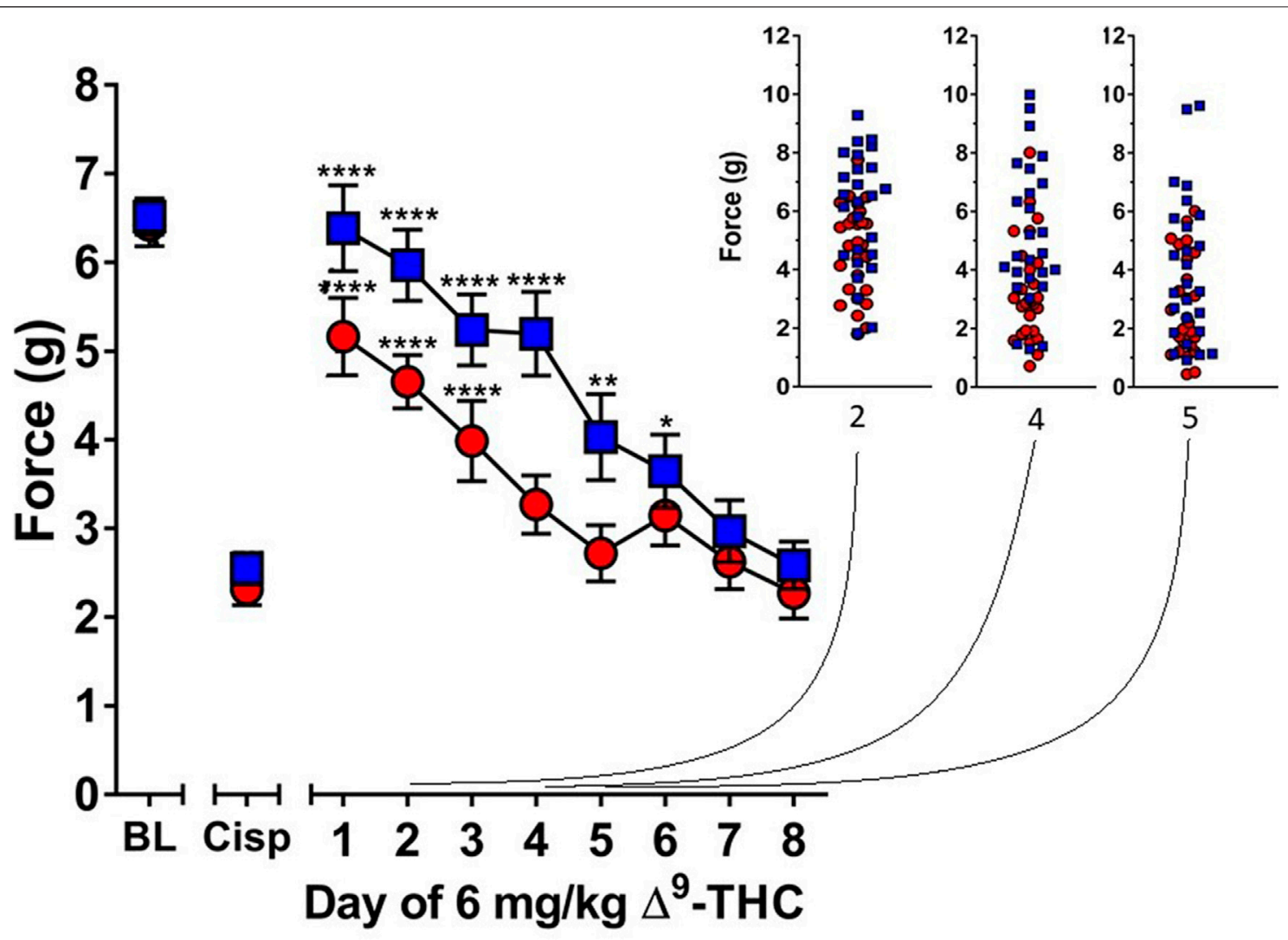

Male Mice (26) O Female Mice (27)

FIGURE 2 | Development of tolerance to the anti-allodynic effects of $6 \mathrm{mg} / \mathrm{kg}$ of $\Delta^{9}-\mathrm{THC}$ in female and male mice. Tolerance to the anti-allodynic effects of $6 \mathrm{mg} / \mathrm{kg}$ $\Delta^{9}$-THC was determined in female (red circles) and male (blue squares) mice collapsed across genotype. Mice were assessed using the von Frey assay for the amount of force (in grams) required to elicit a paw withdrawal response $60 \mathrm{~min}$ following treatment with $6 \mathrm{mg} / \mathrm{kg} \Delta^{9}-\mathrm{THC}$. BL represents the pre-cisplatin baseline and CISP the post-cisplatin baseline. Error bars represent the mean \pm SEM. Each mouse was tested in triplicate and those values averaged to determine a single value for each mouse each day of testing. Data were analyzed using a two-way ANOVAs with Bonferroni post-hoc tests. ${ }^{*} p<0.05 ;{ }^{* *} p>0.01 ;{ }^{* * *} p<0.001 ;{ }^{* * * *} p<0.0001 ;$ compared to the post-cisplatin baseline]. Sample sizes for each group (shown in parentheses) 26 male (13 WT; $13 \mathrm{KI})$ and 27 female (13 WT; $14 \mathrm{KI})$ mice.

0.4013). Separate analyses showed that $10 \mathrm{mg} / \mathrm{kg} \Delta^{9}$-THC resulted in a full reversal of allodynia for both female wildtype and S426A/S430A mice. However, as with $6 \mathrm{mg} / \mathrm{kg}$, there was no difference in the rate of tolerance to $10 \mathrm{mg} / \mathrm{kg}$ of $\Delta^{9}$-THC as a function of genotype, with both mutants and wild-types showing complete tolerance following 4 days of treatment with $10 \mathrm{mg} / \mathrm{kg} \Delta^{9}$-THC (Figure 3).

\section{Tolerance to $10 \mathrm{mg} / \mathrm{kg}$ Delta-9-Tetrahydrocannabinol in Male and Female Wild-Type Mice}

A second group of male and female wild-type mice were assessed for tolerance to the anti-allodynic effects of $10 \mathrm{mg} / \mathrm{kg}$ of $\Delta^{9}$-THC, a dose that fully reversed allodynia in both sexes. As there was no difference in tolerance or sensitivity to either 6 and/or $10 \mathrm{mg} / \mathrm{kg}$ of $\Delta^{9}$-THC in male and female S426A/S430A mice compared to their wild-type counterparts, only wild-type mice were used for all subsequent experiments. In contrast to our previous experiments that did not include a vehicle control, in mice with cisplatin- induced neuropathy, subsequent groups of male and female wildtype mice were injected with vehicle $1 \mathrm{~h}$ prior to being assessed by the von Frey test, after which, they were immediately injected with 6 or $10 \mathrm{mg} / \mathrm{kg}$ of $\Delta^{9}$-THC and assessed again $60 \mathrm{~min}$ later to determine the anti-allodynic effects of $\Delta^{9}$-THC.

Results from a two-way ANOVA (sex x treatment) showed that there was a main effect of cisplatin treatment $\left(F_{1,29}=88.68\right.$, $p<0.001)$ indicating that treatment with cisplatin evoked mechanical allodynia in both sexes (Figure 4). There was also a main effect of sex $\left(F_{1,29}=9.307, p=0.005\right)$ indicating that females displayed lower overall von Frey scores than males. There was not a sex-by-treatment interaction effect $(p=0.86)$ indicating that cisplatin-treatment reduced male and female von Frey test responses by approximately the same amount (65\% in males; $69 \%$ in females). Thus, despite females having slightly lower overall von Frey responses, cisplatin induced approximately the same degree of neuropathy in male and female mice.

Results from a two-way ANOVA (sex $\mathrm{x}$ day) examining whether sex altered the rate of tolerance to $10 \mathrm{mg} / \mathrm{kg} \Delta^{9}$-THC revealed a main effect of day $\left(F_{7,203}=26.49, p<0.001\right)$ and a 


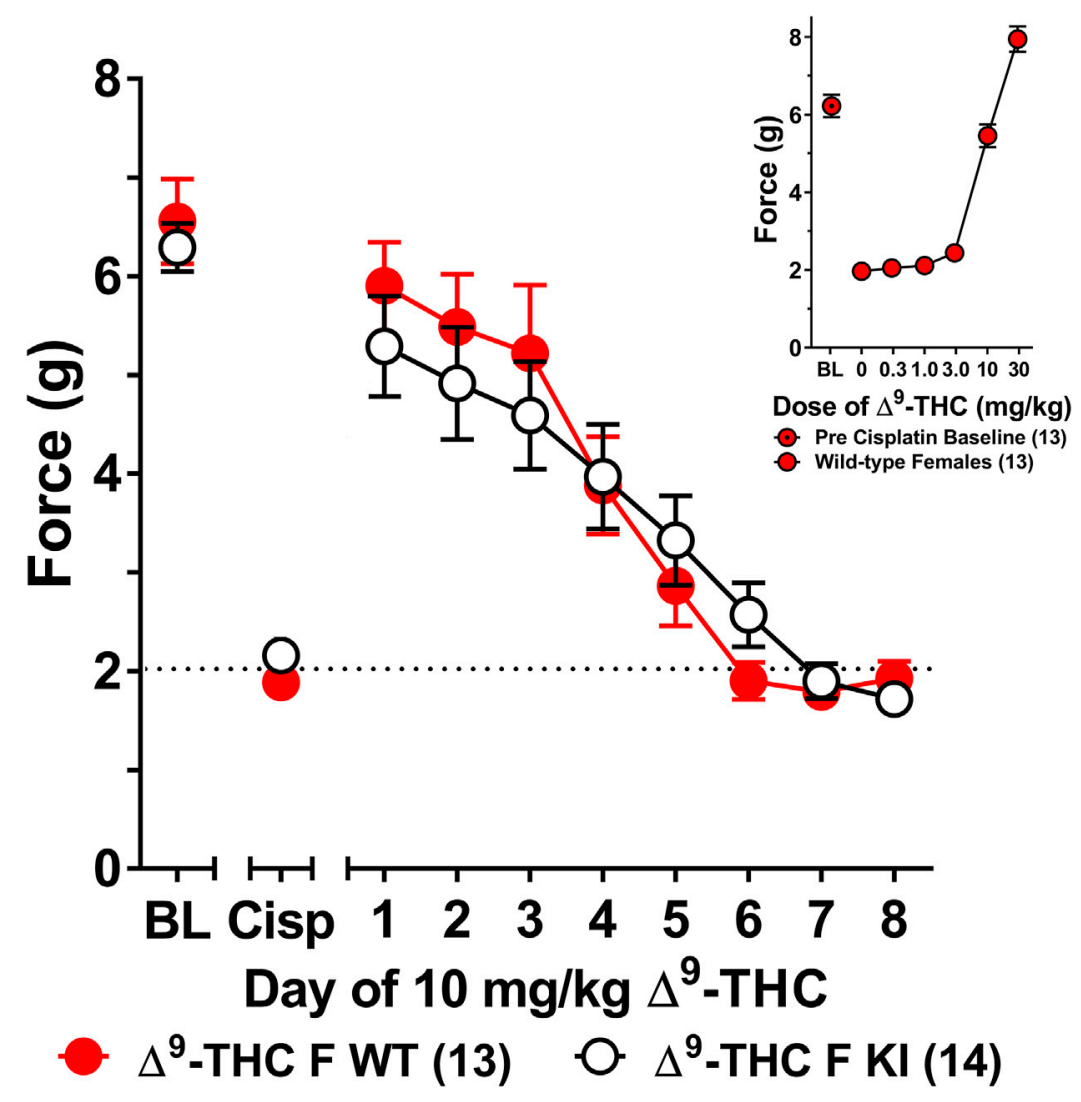

FIGURE 3 | Development of tolerance to the anti-allodynic effects of $10 \mathrm{mg} / \mathrm{kg}$ of $\Delta^{9}$-THC in female wild-type and S426A/S430A mice. Results from a doseresponse (insert) revealed that $10 \mathrm{mg} / \mathrm{kg}$ of $\Delta^{9}$-THC fully reversed allodynia in wild-type females. Tolerance to the anti-allodynic effects of $10 \mathrm{mg} / \mathrm{kg} \Delta^{9}$-THC was determined in female S426A/S430A (KI; unfilled) and wild-type (WT; filled) mice. Mice were assessed using the von Frey assay for the amount of force (in grams) required to elicit a paw withdrawal response $60 \mathrm{~min}$ following treatment with $6 \mathrm{mg} / \mathrm{kg} \Delta^{9}-\mathrm{THC}$. BL represents the pre-cisplatin baseline and CISP the post-cisplatin baseline. Error bars represent the mean \pm SEM. Each mouse was tested in triplicate and those values averaged to determine a single value for each mouse each day of testing. Data were analyzed using separate two-way ANOVAs with Bonferroni post-hoc tests. Sample sizes for each group (shown in parentheses) include 13 female WT mice for the dose response and 13 female WT and 14 female $\mathrm{KI}$ mice for daily tolerance.

significant sex-by-day interaction $(p=0.028)$. Post-hoc analyses showed that $10 \mathrm{mg} / \mathrm{kg} \Delta^{9}$-THC was able to fully reverse mechanical allodynia in both males and females and that females showed a decreased anti-allodynic response to this dose of $\Delta^{9}$-THC on day 4 compared to males $(p=0.005)$. Compared to day 1 of $\Delta^{9}$-THC treatment, females showed evidence of partial tolerance on day 3 whereas males took until day 4 to show evidence of tolerance (Figure 4). Comparison to their own post-cisplatin baseline revealed females were completely tolerant to the anti-allodynic effects of $\Delta^{9}$-THC by day 4 of treatment while males did not display full tolerance until day 6 of treatment.

To ensure tolerance to $\Delta^{9}$-THC was not an artifact of learned behavior (to withdraw their paw), mice were baselined daily following treatment with vehicle prior to treatment with $\Delta^{9}$ THC. Subsequent two-way ANOVAs (treatment $\mathrm{x}$ day) were run comparing the daily response of mice following vehicle and $\Delta^{9}$ THC across each day. For both males and females, there were main effects of treatment (males: $F_{1,14}=80.60, p<0.001$; females: $F_{1,15}=67.39, p<0.001$ ) and day (males: $F_{7,98}=11.17, p<0.001$; females: $\left.F_{7,105}=15.82, p<0.001\right)$, and treatment-by-day interactions (males: $F_{7,98}=12.30, p<0.001$; females: $F_{7,105}=$ 10.86, $p<0.001)$. Post-hoc analyses revealed that these interactions were driven by the difference in anti-allodynic response following treatment with $\Delta^{9}$-THC vs. vehicle. Further, male mice returned to their vehicle-treatment baseline after 7 days of $10 \mathrm{mg} / \mathrm{kg} \Delta^{9}$-THC while females returned to their vehicle-treated baseline after 6 days. These data suggest that when using a dose of $\Delta^{9}$-THC $(10 \mathrm{mg} / \mathrm{kg})$ capable of completely reversing allodynia in both sexes, females are slightly faster to develop tolerance to the anti-allodynic effects of $\Delta^{9}$-THC compared to male littermates (Figure 4).

\section{Tolerance to Equally Efficacious Doses of Delta-9-Tetrahydrocannabinol in Male and Female Wild-Type Mice}

A third group of male and female wild-type mice were assessed for tolerance to the anti-allodynic effects of "equally efficacious doses" of $10 \mathrm{mg} / \mathrm{kg} \Delta^{9}$-THC in females and $6 \mathrm{mg} / \mathrm{kg} \Delta^{9}$-THC in 


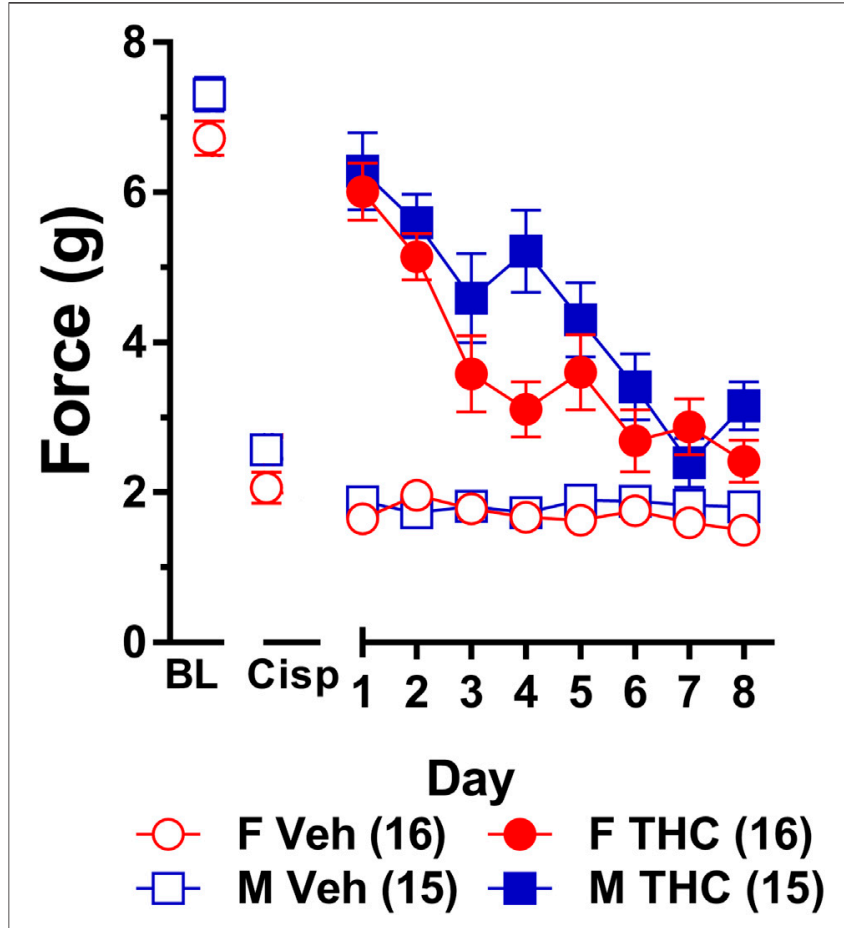

FIGURE 4 | Development of tolerance to the anti-allodynic effects of $10 \mathrm{mg} / \mathrm{kg}$ of $\Delta^{9}$-THC in male and female wild-type mice. Tolerance to the antiallodynic effects of vehicle (unfilled) and $10 \mathrm{mg} / \mathrm{kg}$ (filled) $\Delta^{9}-\mathrm{THC}$ was determined in both male (squares) and female (circles) wild-type (WT) mice using the von Frey. Mice were first assessed for the amount of force (in grams) required to elicit a paw withdrawal response 60 min following treatment with vehicle and $60 \mathrm{~min}$ later following treatment with $10 \mathrm{mg} / \mathrm{kg}$ $\Delta^{9}$-THC. BL represents the pre-cisplatin baseline and CISP the postcisplatin baseline. Error bars represent the mean \pm SEM. Each mouse was tested in triplicate and those values averaged to determine a single value for each mouse for each dose tested on each day of testing. Data were analyzed using separate two-way ANOVAs with Bonferroni post-hoc tests. Sample sizes for each group (shown in parentheses) include 15 male and 16 female WT mice.

males. Results from a two-way ANOVA (sex x treatment) showed that there was a main effect of cisplatin treatment $\left(F_{1,28}=566.5\right.$, $p<0.001)$ indicating that treatment with cisplatin evoked mechanical allodynia in both sexes (Figure 5). There was also a main effect of $\operatorname{sex}\left(F_{1,28}=10.13, p=0.004\right)$ indicating that females displayed lower overall von Frey scores compared to males. However, there was not a sex-by-treatment interaction effect $(p=0.08)$ indicating that cisplatin-treatment reduced male and female von Frey test responses by approximately the same amount (68\% in both males and females). Thus, despite having slightly lower overall von Frey responses, cisplatin induced approximately the same degree of neuropathy in our male and female mice.

Results from a two-way ANOVA (sex $\mathrm{x}$ day) examining whether sex altered the rate of tolerance to mice given equally efficacious doses of $\Delta^{9}$-THC $(6 \mathrm{mg} / \mathrm{kg}$ in males and $10 \mathrm{mg} / \mathrm{kg}$ in females) revealed a main effect of day $\left(F_{7,196}=32.61, p<0.001\right)$ and sex $\left(F_{1,28}=33.96, p<0.001\right)$ but not a significant sex-by-day interaction $(p=0.44)$. Post-hoc analyses showed that 6 and $10 \mathrm{mg} / \mathrm{kg} \Delta^{9}$-THC were able to fully reverse mechanical allodynia in male and female mice, respectively. Post-hoc analyses also determined that male and female mice did not differ in von Frey scores at baseline $(p=0.30)$, following treatment with cisplatin $(p=0.99)$, or on day 1 following treatment with equally efficacious doses $\Delta^{9}$-THC $(p=0.49)$. Despite the lack of a significant sex-by-day interaction, which suggests that males and females did not differ in the rates at which they developed tolerance to $\Delta^{9}$-THC, females showed a rapid and prolonged decrease in response to the anti-allodynic effects of $\Delta^{9}$ THC on days $2(p=0.010), 3(p=0.001), 4(p=0.001), 5(p=$ $0.003)$, and $6(p=0.002)$ compared to their male littermates. Likewise, compared to day 1 of $\Delta^{9}$-THC treatment, females showed evidence of partial tolerance on day 2 whereas males took until day 3 to show evidence of tolerance. Finally, comparison to their own post-cisplatin baseline revealed females were completely tolerant to the anti-allodynic effects of $\Delta^{9}$-THC by day 5 of treatment while males did not display full tolerance until day 7 of treatment (Figure 5). Taken together,

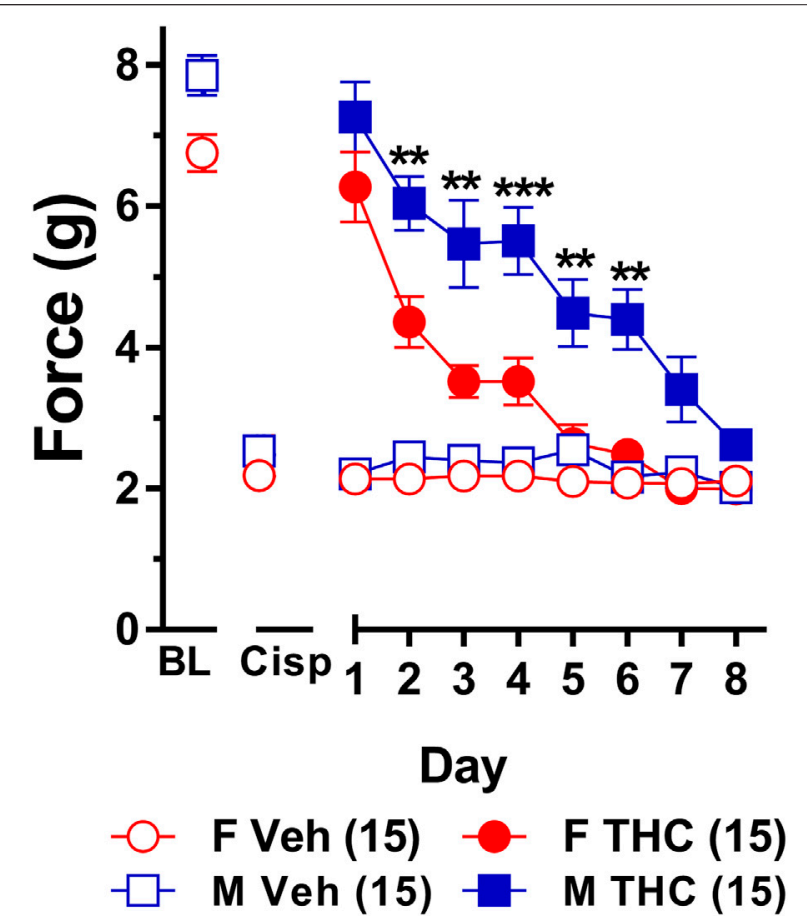

FIGURE 5 | Development of tolerance to equally efficacious doses of $\Delta^{9}$ THC in male and female wild-type mice. Tolerance to the anti-allodynic effects of vehicle (unfilled) and equally efficacious doses of $\Delta^{9}-\mathrm{THC}$ (filled) was determined in both male (squares) and female (circles) wild-type (WT) mice using the von Frey. Mice were first assessed for the amount of force (in grams) required to elicit a paw withdrawal response $60 \mathrm{~min}$ following treatment with vehicle and 60 min later following treatment with $10 \mathrm{mg} / \mathrm{kg}$ (female) or $6 \mathrm{mg} / \mathrm{kg}$ (male) of $\Delta^{9}$-THC. BL represents the pre-cisplatin baseline and CISP the post-cisplatin baseline. Error bars represent the mean \pm SEM. Each mouse was tested in triplicate and those values averaged to determine a single value for each mouse for each dose on each day testing. Data were analyzed using separate two-way ANOVAs with Bonferroni post-hoc tests. $\left({ }^{\star \star} p>0.01 ;{ }^{* \star} p<0.001\right.$; compared to females on the same day). Sample sizes for each group (shown in parentheses) include 15 male and 15 female WT mice. 

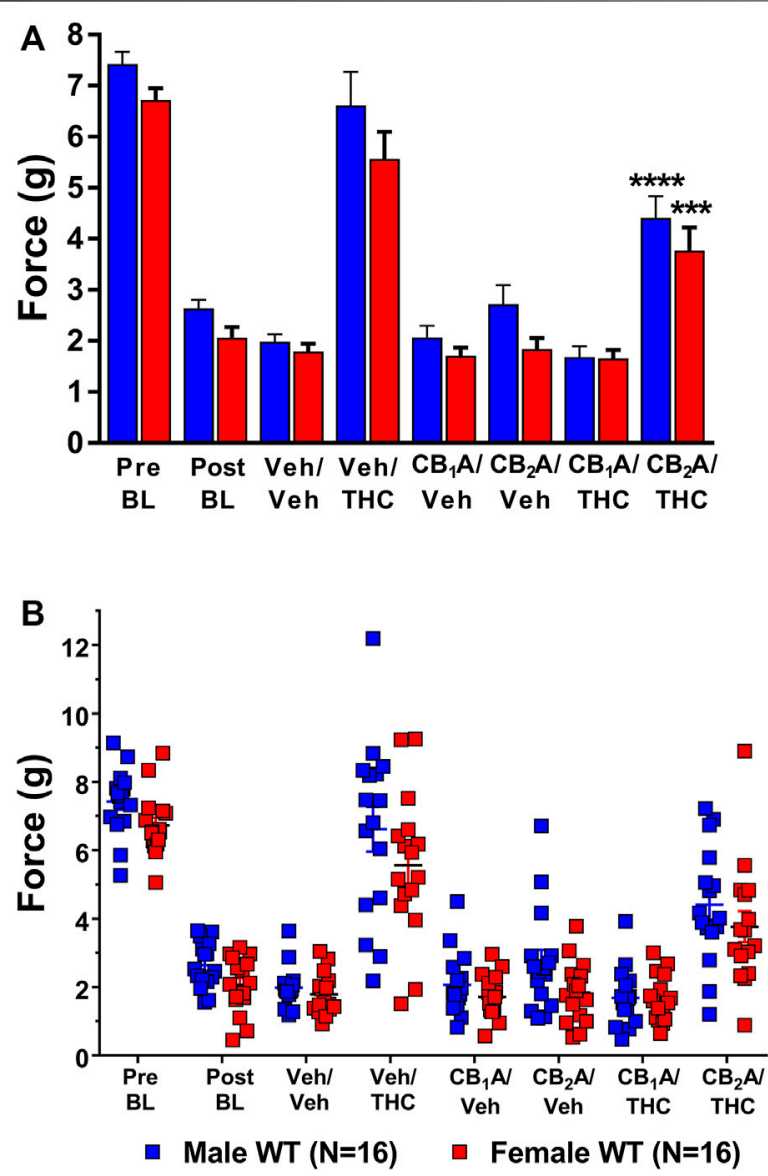

FIGURE 6 | Mediation of the anti-allodynic effects of $10 \mathrm{mg} / \mathrm{kg} \Delta^{9}-\mathrm{THC}$ by $\mathrm{CB}_{1}$ and/or $\mathrm{CB}_{2}$ receptors. (A) Aggregate and (B) Individual Plots graphs showing male (blue squares) and female (red circle) wild-type (WT) mice showed a full reversal of allodynia following pretreatment with $10 \mathrm{mg} / \mathrm{kg}$ of $\Delta^{9}$-THC. Mice were treated and then assessed for the amount of force $(\mathrm{g})$ required to elicit a paw withdrawal response $30 \mathrm{~min}$ are pretreatment with either vehicle, $10 \mathrm{mg} / \mathrm{kg}$ of the $\mathrm{CB}_{1}$ receptor inverse agonist SR141716A, or $10 \mathrm{mg} / \mathrm{kg}$ of the $\mathrm{CB}_{2}$ receptor inverse agonist SR144528 and again $60 \mathrm{~min}$ following treatment with either vehicle or $10 \mathrm{mg} / \mathrm{kg} \Delta^{9}-\mathrm{THC}$. Error bars represent the mean \pm SEM. Each mouse was tested in triplicate and those values averaged to determine a single value for each mouse each day of testing. Data were analyzed using a two-way ANOVA with Bonferroni posthoc tests. [ ${ }^{\star \star *} p<0.001$; ${ }^{* * *} p<0.0001$; compared to both pre- (Pre) and post(Post) Cisplatin baselines (BL)]. Sample sizes for each dosing combination (shown in parentheses) include 16 male and 16 female WT mice.

these data suggest that despite a nonsignificant sex-by-day interaction, female mice developed tolerance to the antiallodynic effects of equally efficacious doses of $\Delta^{9}$-THC more rapidly than their male counterparts.

To establish that tolerance to $\Delta^{9}$-THC was not an artifact of learned behavior (to withdraw their paw), mice were baselined daily following treatment with vehicle prior to treatment with $\Delta^{9}$ THC. Subsequent two-way ANOVAs (treatment $x$ day) were run comparing the daily response of mice following vehicle and $\Delta^{9}$ THC across each day. For both males and females, there were main effects of treatment (males: $F_{1,14}=152.6, p<0.001$; females: $F_{1,14}=203.3, p<0.001$ ) and day (males: $F_{7,98}=11.44, p<0.001$; females: $\left.F_{7,98}=22.08, p<0.001\right)$, and treatment-by-day interactions (males: $F_{7,98}=12.35, p<0.001$; females: $F_{7,98}=$ 18.72, $p<0.001$ ). Post-hoc analyses revealed that these interactions were driven by the difference in anti-allodynic response following treatment with $\Delta^{9}$-THC vs. vehicle. Further, male mice returned to their vehicle-treatment baseline after 7 days of $6 \mathrm{mg} / \mathrm{kg} \Delta^{9}$-THC while females returned to their vehicle-treated baseline after 5 days of $10 \mathrm{mg} / \mathrm{kg} \Delta^{9}$-THC. These data suggest that when using equally efficacious doses of $\Delta^{9}$-THC capable of completely reversing allodynia in both sexes $(10 \mathrm{mg} / \mathrm{kg}$ in females and $6 \mathrm{mg} / \mathrm{kg}$ in males), females are slightly faster to develop tolerance to the anti-allodynic effects of $\Delta^{9}$-THC compared to male littermates (Figure 5).

\section{Use of $\mathrm{CB}_{\mathbf{1}}$ and $\mathrm{CB}_{\mathbf{2}}$ Receptor Antagonists}

Since $\Delta^{9}$-THC is a mixed agonist capable of acting at both the $\mathrm{CB}_{1}$ and $\mathrm{CB}_{2}$ receptors, this experiment determined which receptors mediated the anti-allodynic effects of $\Delta^{9}$-THC. Mice were pretreated with either the selective $C_{1}$ receptor inverse agonist rimonabant, the $\mathrm{CB}_{2}$ receptor inverse agonist SR144528, or vehicle prior to treatment with either $10 \mathrm{mg} / \mathrm{kg} \Delta^{9}$-THC or vehicle. Results from a two-way ANOVA (sex $\mathrm{x}$ treatment combination) revealed main effects of $\operatorname{sex}\left(F_{1,30}=10.73, p=0.003\right)$ and treatment combination $\left(F_{7,102}=86.51, p<0.001\right)$ but not a significant interaction ( $p=0.771$; Figure 6).

Post-hoc analysis revealed that treatment with vehicle alone did not differ from the post-cisplatin baseline in either male ( $p=$ $0.8349)$ or female $(p=0.9988)$ mice. Treatment with either the $\mathrm{CB}_{1}$ receptor inverse agonist rimonabant or the $\mathrm{CB}_{2}$ receptor inverse agonist, SR144528, alone also did not differ from vehicle treatment in either male $\left[\mathrm{CB}_{1}(p=0.9999) ; \mathrm{CB}_{2}(p=0.7384)\right]$ or female $\left[\mathrm{CB}_{1}(p=0.9999) ; \mathrm{CB}_{2}(p=0.9999)\right]$ mice. Treatment with $10 \mathrm{mg} / \mathrm{kg}$ of $\Delta^{9}$-THC alone was able to fully reverse mechanical allodynia in both male and female mice to their pre-cisplatin baseline levels, and this effect was completely blocked in both male and female mice by pretreatment with rimonabant. Interestingly, pretreatment with the $\mathrm{CB}_{2}$ receptor inverse agonist partially blocked the ability of $\Delta^{9}$-THC to reverse these effects (Figure 6). These results suggest a strong role for $\mathrm{CB}_{1}$ receptors and a partial role for $\mathrm{CB}_{2}$ receptors in mediating the anti-allodynic effects of $\Delta^{9}$-THC in mice with cisplatin-induced neuropathic pain. The lack of an interaction effect suggests that sex differences observed in $\Delta^{9}$ THC tolerance were not due to differences in cannabinoid receptor mediation.

\section{DISCUSSION}

The first goal of this study was to determine whether blocking the GRK/ $\beta$-arrestin-2 pathway of desensitization using the S426A/ S430A mutant mice altered sensitivity and/or tolerance to $\Delta^{9}$ THC in a clinically relevant model of chronic pain. The second goal was to determine whether there were any sex differences in tolerance to the anti-allodynic effects of $\Delta^{9}$-THC in this pain model. We found that disruption of the GRK/ $\beta$-arrestin-2 
pathway of desensitization did not alter sensitivity and/or tolerance to the anti-allodynic effects of either 6 or $10 \mathrm{mg} / \mathrm{kg}$ of $\Delta^{9}$-THC in a model of cisplatin-evoked neuropathy. We also found that female mice developed tolerance to the anti-allodynic effects of both 6 and $10 \mathrm{mg} / \mathrm{kg} \Delta^{9}$-THC faster than male littermates.

The finding that the S426A/S430A mutation failed to alter either sensitivity and/or tolerance to $\Delta^{9}$-THC was not entirely surprising. Previous studies in our lab have shown that male mice expressing the S426A/S430A mutation show a greater antinociceptive response and/or delayed tolerance development to $\Delta^{9}$-THC (Morgan et al., 2014; HendersonRedmond et al., 2020), CP55,940 (LaFleur et al., 2018; Nealon et al., 2019), and WIN55,212-2 (Nealon et al., 2019) compared to their wild-type littermates in acute models of thermal (tail-flick) and inflammatory (formalin) pain. In contrast, studies examining whether the S426A/S430A mutation can alter tolerance to $\mathrm{CB}_{1}$ receptor agonists in a model of cisplatin-evoked neuropathy have been mixed, with the S426A/S430A mutation altering tolerance development to WIN55,212-2 but not CP55,940 (Nealon et al., 2019). However, the delay in tolerance to WIN55,212-2 in the S426A/S430A mutants was much more modest in the chronic pain model than in the acute model (Nealon et al., 2019).

The inability of the S426A/S430A mutation to confer enhanced anti-allodynic effects and/or delayed tolerance to 6 or $10 \mathrm{mg} / \mathrm{kg}$ of $\Delta^{9}$-THC (a mixed $\mathrm{CB}_{1} / \mathrm{CB}_{2}$ receptor agonist) in these experiments is likely due to the anti-allodynic effects of $\Delta^{9}$ $\mathrm{THC}$ at $\mathrm{CB}_{2}$ receptors which do not undergo tolerance (Deng et al., 2015) and are known to be upregulated in models of chronic pain (Zhang et al., 2003; Wotherspoon et al., 2005; Beltramo et al., 2006). In our previous studies examining the acute antinociceptive effects of $\Delta^{9}$-THC, we found that the antinociceptive effects of $\Delta^{9}$-THC in the tail-flick assay was exclusively mediated by $\mathrm{CB}_{1}$ receptors (Henderson-Redmond et al., 2020). However, mixed $\mathrm{CB}_{1} / \mathrm{CB}_{2}$ receptor agonists have been shown to suppress vincristine-evoked (Rahn et al., 2009) and cisplatin-evoked (Vera et al., 2013) mechanical allodynia through action at both $\mathrm{CB}_{1}$ and $\mathrm{CB}_{2}$ receptors. Therefore, to better investigate the role of $G R K / \beta$-arrestin-2-mediated $C_{1}$ receptor desensitization in cannabinoid tolerance using the cisplatin model, we used selective $\mathrm{CB}_{1}$ and $\mathrm{CB}_{2}$ receptor inverse agonists to delineate the contribution of each receptor. We found that pretreatment with the selective $\mathrm{CB}_{1}$ receptor inverse agonist rimonabant completely blocked $\Delta^{9}$-THCinduced anti-allodynia. However, pretreatment with the selective $\mathrm{CB}_{2}$ receptor inverse agonist, SR144528, partially blocks the anti-allodynic effects of $\Delta^{9}$-THC, confirming work by other groups showing a greater role of $\mathrm{CB}_{2}$ receptors in models of chronic neuropathic vs. acute pain states. Taken together, differential activation of $\mathrm{CB}_{1}$ and $\mathrm{CB}_{2}$ receptors by different cannabinoid agonists could help explain why we observe differences in the ability of the S426A/S430A mutation to alter anti-allodynic responses to select cannabinoid agonists in mice with cisplatin-evoked neuropathy.

Upregulation of $\mathrm{CB}_{2}$ receptors, but not $\mathrm{CB}_{1}$ receptors, has been observed in the spinal cord (Zhang et al., 2003; Hsieh et al., 2011) and in dorsal root ganglia (Hsieh et al., 2011) following peripheral nerve injury using chronic constriction injury or spinal nerve ligation approaches. Additional work shows that microglia and astrocyte activation contribute to the onset and maintenance of neuropathic pain (Watkins et al., 2001; Guo et al., 2007) due to their ability to elicit the release of cytokines, including IL-1 $\beta$, IL- 6 , and TNF- $\alpha$, which can enhance pain responses and maintain a neuropathic pain state (Milligan et al., 2001, 2003). Likewise, there is increasing preclinical evidence to suggest that targeting $\mathrm{CB}_{2}$ receptors may be more efficacious in alleviating chronic neuropathic pain with fewer side effects than the use of $\mathrm{CB}_{1}$ receptor agonists (for a review, see Guindon and Hohmann 2008). Taken together, it is likely that our $\Delta^{9}$-THC-induced anti-allodynia is being mediated, at least in part, through $\mathrm{CB}_{2}$ receptors.

Peripheral $\mathrm{CB}_{1}$ receptors have been shown to modulate neuropathic pain (Fox et al., 2001; Toth et al., 2010; Starowicz et al., 2012; Deng et al., 2015). Mutant mice lacking $\mathrm{CB}_{1}$ in peripheral nociceptors revealed that endocannabinoid-induced antinociception was mediated via $\mathrm{CB}_{1}$ expressed in these neurons in mouse models of inflammatory and neuropathic pain (Agarwal et al., 2007). Likewise, the endocannabinoid, anandamide, has been shown to reduce cisplatin-induced hyperalgesia through activation of peripheral $\mathrm{CB}_{1}$ receptors (Khasabova et al., 2012). Despite evidence of at least partial mediation by $\mathrm{CB}_{2}$, pretreatment with the $\mathrm{CB}_{1}$ inverse agonist, rimonabant, was able to fully reverse the anti-allodynic effects of $10 \mathrm{mg} / \mathrm{kg} \Delta^{9}$ THC, highlighting the importance of $\mathrm{CB}_{1}$ receptors in a model of cisplatin-evoked neuropathy. Although preclinical work in rodents supports a role for both $\mathrm{CB}_{1}$ and $\mathrm{CB}_{2}$, through the use of both receptor-selective (Deng et al., 2012; Vera et al., 2013) and/or mixed $\mathrm{CB}_{1} / \mathrm{CB}_{2}$ agonists (Vera et al., 2013; Nealon et al., 2019; Henderson-Redmond et al., 2020) in mediating cisplatin-induced neuropathy, results of clinical work are slightly less clear.

Clinically, studies appear to support a role for cannabinoids, including $\Delta^{9}$-THC, for the treatment of chronic, noncancer pain (for a review see, Wong et al., 2020). For example, Nabilone, an FDA approved analog of $\Delta^{9}$-THC for the treatment of chemotherapy-induced nausea and vomiting, was found to be superior to both placebo and/or an active control in relieving pain associated with chronic headaches (Pini et al., 2012), diabetic neuropathy (Toth et al., 2012), and Multiple Sclerosis (MS)-induced chronic pain (Turcotte et al., 2015). Likewise, smoked cannabis containing $4 \% \Delta^{9}$-THC and vaporized cannabis containing either $1.29 \%$ or $3.53 \% \Delta^{9}$ THC were found to be superior to placebo in attenuating MS spasticity and pain (Corey-Bloom et al., 2012) and in managing neuropathic pain in subjects with varying types of neuropathic pain (Wilsey et al., 2013) (for a review see Lynch and Ware, 2015). A second assessment of the efficacy of medical marijuana for noncancer, neuropathic pain found that while medical marijuana provides short-term pain relief on chronic pain, longer studies need to be done to assess whether the analgesic effects of marijuana persist or dissipate with continued use over time (Deshpande et al., 2015). 
In contrast, few clinical trials have examined the role of cannabinoids in managing chemotherapy-evoked neuropathy making it difficult to draw conclusions on the efficacy of $\Delta^{9}$ THC in managing CENP. For example, a recent study found that use of Sativex ${ }^{\circledR}$, the oral mucosal spray containing cannabinoids, was not much more effective than placebo alone in patients that had neuropathic pain persisting at least three months post-chemotherapy (Lynch et al., 2014). However, not only was the sample size in this pilot extremely small (16 participants), but five of the participants showed a large (at least a two-point) decrease in pain according to a numerical rating scale for pain intensity (NRS-PI). Further, 10 patients continued in the study extension, and at 3 and 6 months, those patients that continued with the study saw even greater reductions in pain with NRS-PI scores of 6.9 at baseline reduced to 5.0 and 4.2 at 3 and 6 months, respectively (Lynch et al., 2014). The results of this study suggest that clinically, cannabinoids may be especially beneficial to a subset of those suffering from CENP. Interestingly, patients in the previous study were not differentiated based on the type of chemotherapy received. A recent preclinical finding, however, suggests that different cannabinoids (CBD vs. $\Delta^{9}$ THC) may be selective in their efficacy for alleviating neuropathies induced by different chemotherapies (King et al., 2017). Taken together, it is possible that different subsets of individuals may be more responsive to different types of cannabinoid-based treatments depending on the type of chemotherapy administered to treat their cancer. One limitation, however, of using animal models to assess the efficacy of $\Delta^{9}$-THC and other cannabinoids in treating CENP is that, unlike patients that undergo chemotherapy to treat cancer and subsequently develop neuropathies as a consequence, these animals do not have cancer prior to receiving chemotherapy. Thus, while we can use animal models to gain valuable insight into the potential for cannabinoids (or other drugs) to manage CENP, clinical CENP may be more difficult to treat given the differences in etiology that can occur following the effects of various cancers on the body, ultimately limiting their utility.

Consistent with previous studies, we found that females developed tolerance to the anti-allodynic effects of $\Delta^{9}$-THC faster than their male counterparts (Wakley et al., 2014b). Specifically, we found that female wild-type mice were fully tolerant to the effects of $6 \mathrm{mg} / \mathrm{kg} \Delta^{9}$-THC after 4 days of treatment whereas male mice were not tolerant until day 7 of $\Delta^{9}$-THC treatment (Figure 2). Unsure whether this observed effect was confounded due to differences in acute efficacy for the anti-allodynic effects of $\Delta^{9}$-THC, we reassessed tolerance using $10 \mathrm{mg} / \mathrm{kg} \Delta^{9}$-THC, a dose that fully reversed mechanical allodynia in both male and female mice. As with $6 \mathrm{mg} / \mathrm{kg} \Delta^{9}$ THC, we observed faster tolerance to $10 \mathrm{mg} / \mathrm{kg} \Delta^{9}$-THC in female mice as they displayed complete tolerance after 4 days while males did not display tolerance until day 6 of $10 \mathrm{mg} / \mathrm{kg} \Delta^{9}$ THC treatment (Figure 4). Likewise, when seeking to establish differences in tolerance using equally efficacious doses, we confirmed the finding that females developed tolerance to $\Delta^{9}$ THC more rapidly than male littermates (Figure 5).
Evidence suggests that sex differences in the antinociceptive effects of $\Delta^{9}$-THC might be due to differences in the relative expression of $\mathrm{CB}_{1}$ and $\mathrm{CB}_{2}$ receptors (Craft et al., 2012). For example, Craft et al. (2012) found that while acute $\Delta^{9}$-THCmediated antinociception was mediated primarily via $\mathrm{CB}_{1}$ receptors in male rats, it was mediated by both $\mathrm{CB}_{1}$ and $\mathrm{CB}_{2}$ receptors in females. Another possibility is that differences in hormonal signaling might modulate establishment of allodynia, cannabinoid response, and tolerance. Preclinical rodent studies showed that testosterone can reduce inflammatory pain (Da Silva et al., 1993), dampen the immune response to experimentally induced inflammatory pain (Gaillard and Spinedi, 1998), and protect against the development of chronic pain development (Fischer et al., 2007; Schertzinger et al., 2018). Ovary intact Sprague-Dawley female rats exhibit elevated tactile allodynia compared to male rats and ovariectoimzed females (Coyle et al., 1995; Coyle et al., 1996) following partial sciatic nerve ligation. Chemotherapyevoked mechanical allodynia was also enhanced in female Sprague-Dawley rats compared to male rats (Joseph and Levine, 2003). Ovariectomization decreased mechanical allodynia in female rats to a level observed in males while estrogen-replacement therapy restored elevated mechanical allodynia (Joseph and Levine, 2003). These data suggest that testosterone may offer a protective effect while estrogen may predispose females towards developing allodynia following chronic injury.

In contrast, several studies seem to indicate that estrogen, specifically estradiol, may enhance the antinociceptive and antiallodynic effects of $\Delta^{9}$-THC. For example, female rats have been shown to be more sensitive to the antinociceptive effects of $\Delta^{9}$ THC compared to males across a host of acute, inflammatory, and chronic pain states (Tseng and Craft, 2001; Craft et al., 2004; Craft and Leitl, 2008; Craft et al., 2012; Craft et al., 2013; Wakley et al., 2015). Likewise, estradiol enhancement of $\Delta^{9}$-THCinduced antinociception in mechanical allodynia has been demonstrated in ovariectomized female rats (Craft and Leitl, 2008; Wakley et al., 2014a) and estrus has been shown to enhance the antinociceptive effects of $\Delta^{9}$-THC when estrogen levels are higher (Craft and Leitl, 2008; Wakley and Craft, 2011). However, this same group determined that while hormones could alter $\Delta^{9}$-THC-mediated antinociception acutely (Craft and Leitl, 2008; Wakley et al., 2014a, Wakley et al., 2015) and that chronic $\Delta^{9}$-THC administration could suppress female cycling (Marusich et al., 2015), hormones did not affect tolerance to $\Delta^{9}$-THC (Wakley et al., 2015). Thus, the interplay of hormones on pain, cannabinoid-mediated antinociception, and tolerance is a complex issue that future studies should address.

In contrast to our previous studies in acute pain models, disruption of GRK- $\beta$-arrestin-2-induced desensitization of $\mathrm{CB}_{1}$ receptors failed to alter sensitivity to and/or tolerance to 6 and/ or $10 \mathrm{mg} / \mathrm{kg} \Delta^{9}$-THC in male or female mice within a model of chronic, cisplatin-evoked neuropathic pain. Interestingly, female mice were less sensitive and faster to develop tolerance to the anti-allodynic effects of 6 and $10 \mathrm{mg} / \mathrm{kg} \Delta^{9}$ THC compared to their male littermates. As such, it is likely 
that tolerance to cannabinoids is impacted to a much greater extent by $\mathrm{CB}_{2}$ receptors in a cisplatin-evoked model of neuropathic pain. Given that women have a higher incidence and often present with a greater prevalence of chronic and neuropathic pain conditions compared to men, we surmise that sex should be thoroughly evaluated when assessing the therapeutic potential of cannabinoids for pain management.

\section{DATA AVAILABILITY STATEMENT}

The raw data supporting the conclusion of this article will be made available by the authors, without undue reservation.

\section{ETHICS STATEMENT}

The animal study was reviewed and approved by the Marshall University Institutional Animal Care and Use Committee (IACUC) and the Pennsylvania State University Institutional Animal Care and Use Committee (IACUC).

\section{REFERENCES}

Agarwal, N., Pacher, P., Tegeder, I., Amaya, F., Constantin, C. E., Brenner, G. J., et al. (2007). Cannabinoids Mediate Analgesia Largely via Peripheral Type 1 Cannabinoid Receptors in Nociceptors. Nat. Neurosci. 10, 870-879. doi:10.1038/nn1916

Arnér, S., and Meyerson, B. A. (1988). Lack of Analgesic Effect of Opioids on Neuropathic and Idiopathic Forms of Pain. Pain 33, 11-23. doi:10.1016/03043959(88)90198-4

Authier, N., Gillet, J. P., Fialip, J., Eschalier, A., and Coudore, F. (2003). An Animal Model of Nociceptive Peripheral Neuropathy Following Repeated Cisplatin Injections. Exp. Neurol. 182, 12-20. doi:10.1016/S0014-4886(03)00003-7

Bass, C. E., and Martin, B. R. (2000). Time Course for the Induction and Maintenance of Tolerance to $\Delta 9$-tetrahydrocannabinol in Mice. Drug Alcohol Depend. 60, 113-119. doi:10.1016/S0376-8716(99)00150-7

Beltramo, M., Bernardini, N., Bertorelli, R., Campanella, M., Nicolussi, E., Fredduzzi, S., et al. (2006). CB2 Receptor-Mediated Antihyperalgesia: Possible Direct Involvement of Neural Mechanisms. Eur. J. Neurosci. 23, 1530-1538. doi:10.1111/j.1460-9568.2006.04684.x

Corey-Bloom, J., Wolfson, T., Gamst, A., Jin, S., Marcotte, T. D., Bentley, H., et al. (2012). Smoked Cannabis for Spasticity in Multiple Sclerosis: A Randomized, Placebo-Controlled Trial. CMAJ 184, 1143-1150. doi: $10.1503 / \mathrm{cmaj} .110837$

Coyle, D. E., Sehlhorst, C. S., and Mascari, C. (1995). Female Rats Are More Susceptible to the Development of Neuropathic Pain Using the Partial Sciatic Nerve Ligation (PSNL) Model. Neurosci. Lett. 186, 135-138. doi:10.1016/03043940(95)11304-F

Coyle, D. E., Susan Sehlhorst, C., and Behbehani, M. M. (1996). Intact Female Rats Are More Susceptible to the Development of Tactile Allodynia Than Ovariectomized Female Rats Following Partial Sciatic Nerve Ligation (PSNL). Neurosci. Lett. 203, 37-40. doi:10.1016/0304-3940(95)12259-1

Craft, R. M., Kandasamy, R., and Davis, S. M. (2013). Sex Differences in Antiallodynic, Anti-hyperalgesic and Anti-edema Effects of $\Delta 9$ tetrahydrocannabinol in the Rat. Pain 154, 1709-1717. doi:10.1016/ j.pain.2013.05.017

Craft, R. M., and Leitl, M. D. (2008). Gonadal Hormone Modulation of the Behavioral Effects of $\Delta$ 9-tetrahydrocannabinol in Male and Female Rats. Eur. J. Pharmacol. 578, 37-42. doi:10.1016/j.ejphar.2007.09.004

\section{AUTHOR CONTRIBUTIONS}

AH-R designed the experiments and wrote the manuscript in combination with DM who also provided the funding for the manuscript. AH-R, LC, DS, DH, and JL all assisted in inducing neuropathy in the mice and in the data collection of the included figures as well as edited drafts of the manuscript. Specifically, DS and DH aided in the collection of the data for Figures 1-3 and LC and JL in Figures 4-6. DS also aided AH-R in the breeding and genotyping of all the mice utilized in the studies contained in the manuscript.

\section{FUNDING}

This research was supported by the National Institute on Drug Abuse grant DA037355 (DM), DA044999 (DM), the Penn State University College of Medicine Department of Anesthesiology and Perioperative Medicine, Marshall University's Department of Biomedical Sciences, and also by a grant from the Pennsylvania Department of Health using CURE Tobacco Settlement Funds (DM).

Craft, R. M., Mogil, J. S., and Aloisi, A. M. (2004). Sex Differences in Pain and Analgesia: the Role of Gonadal Hormones. Eur. J. Pain 8, 397-411. doi:10.1016/ j.ejpain.2004.01.003

Craft, R. M., Wakley, A. A., Tsutsui, K. T., and Laggart, J. D. (2012). Sex Differences in Cannabinoid 1 vs. Cannabinoid 2 Receptor-Selective Antagonism of Antinociception Produced by $\Delta 9$-Tetrahydrocannabinol and CP55,940 in the Rat. J. Pharmacol. Exp. Ther. 340, 787-800. doi:10.1124/jpet.111.188540

Cuttler, C., Mischley, L. K., and Sexton, M. (2016). Sex Differences in Cannabis Use and Effects: A Cross-Sectional Survey of Cannabis Users. Cannabis Cannabinoid Res. 1, 166-175. doi:10.1089/can.2016.0010

D’Souza, D. C., Ranganathan, M., Braley, G., Gueorguieva, R., Zimolo, Z., Cooper, T., et al. (2008). Blunted Psychotomimetic and Amnestic Effects of delta-9-tetrahydrocannabinol in Frequent Users of Cannabis. Neuropsychopharmacology 33, 2505-2516. doi:10.1038/sj.npp.1301643

Da Silva, J. A. P., Peers, S. H., Perretti, M., and Willoughby, D. A. (1993). Sex Steroids Affect Glucocorticoid Response to Chronic Inflammation and to Interleukin-1. J. Endocrinol. 136, 389-397. doi:10.1677/joe.0.1360389

Daigle, T. L., Kearn, C. S., and Mackie, K. (2008). Rapid CB1 Cannabinoid Receptor Desensitization Defines the Time Course of ERK1/2 MAP Kinase Signaling. Neuropharmacology 54, 36-44. doi:10.1016/j.neuropharm.2007.06.005

Dellemijn, P. (1999). Are Opioids Effective in Relieving Neuropathic Pain?. Pain 80, 453-462. doi:10.1016/S0304-3959(98)00256-5

Deng, L., Cornett, B. L., Mackie, K., and Hohmann, A. G. (2015). CB1 Knockout Mice Unveil Sustained CB2-Mediated Antiallodynic Effects of the Mixed CB1/ CB2 Agonist CP55,940 in a Mouse Model of Paclitaxel-Induced Neuropathic Pain. Mol. Pharmacol. 88, 64-74. doi:10.1124/mol.115.098483

Deng, L., Guindon, J., Vemuri, V. K., Thakur, G. A., White, F. A., Makriyannis, A., et al. (2012). The Maintenance of Cisplatin- and Paclitaxel-Induced Mechanical and Cold Allodynia Is Suppressed by Cannabinoid CB2 Receptor Activation and Independent of CXCR4 Signaling in Models of Chemotherapy-Induced Peripheral Neuropathy. Mol. Pain 8, 1744-8069. doi:10.1186/1744-8069-8-71

Deshpande, A., Mailis-Gagnon, A., Zoheiry, N., and Lakha, S. F. (2015). Efficacy and Adverse Effects of Medical Marijuana for Chronic Noncancer Pain Systematic Review of Randomized Controlled Trials. Canabidal Family Physician 61 (8), e372-e381.

Ehlers, C. L., Gizer, I. R., Vieten, C., Gilder, D. A., Stouffer, G. M., Lau, P., et al. (2010). Cannabis Dependence in the San Francisco Family Study: Age of Onset of Use, DSM-IV Symptoms, Withdrawal, and Heritability. Addict. Behaviors 35, 102-110. doi:10.1016/j.addbeh.2009.09.009 
Fallon, M. T., and Colvin, L. (2013). Neuropathic Pain in Cancer. Br. J. Anaesth. 111, 105-111. doi:10.1093/bja/aet208

Fillingim, R. B., King, C. D., Ribeiro-Dasilva, M. C., Rahim-Williams, B., and Riley, J. L. (2009). Sex, Gender, and Pain: A Review of Recent Clinical and Experimental Findings. The J. Pain 10, 447-485. doi:10.1016/ j.jpain.2008.12.001

Fischer, L., Clemente, J. T., and Tambeli, C. H. (2007). The Protective Role of Testosterone in the Development of Temporomandibular Joint Pain. J. Pain 8, 437-442. doi:10.1016/j.jpain.2006.12.007

Fox, A., Kesingland, A., Gentry, C., McNair, K., Patel, S., Urban, L., et al. (2001). The Role of central and Peripheral Cannabinoid1 Receptors in the Antihyperalgesic Activity of Cannabinoids in a Model of Neuropathic Pain. Pain 92, 91-100. doi:10.1016/S0304-3959(00)00474-7

Gaillard, R. C., and Spinedi, E. (1998). Sex- and Stress-Steroids Interactions and the Immune System: Evidence for a Neuroendocrine-Immunological Sexual Dimorphism. Domest. Anim. Endocrinol. 15, 345-352. doi:10.1016/S07397240(98)00028-9

Gorelick, D. A., Levin, K. H., Copersino, M. L., Heishman, S. J., Liu, F., Boggs, D. L., et al. (2012). Diagnostic Criteria for Cannabis Withdrawal Syndrome. Drug Alcohol Depend. 123, 141-147. doi:10.1016/j.drugalcdep.2011.11.007

Gregg, R. W., Molepo, J. M., Monpetit, V. J., Mikael, N. Z., Redmond, D., Gadia, M., et al. (1992). Cisplatin Neurotoxicity: The Relationship between Dosage, Time, and Platinum Concentration in Neurologic Tissues, and Morphologic Evidence of Toxicity. J. Clin. Oncol. 10, 795-803. doi:10.1200/JCO.1992.10.5.795

Guindon, J., Deng, L., Fan, B., Wager-Miller, J., and Hohmann, A. G. (2014). Optimization of a Cisplatin Model of Chemotherapy-Induced Peripheral Neuropathy in Mice: Use of Vitamin C and Sodium Bicarbonate Pretreatments to Reduce Nephrotoxicity and Improve Animal Health Status. Mol. Pain 10, 1744-8069. doi:10.1186/1744-8069-10-56

Guindon, J., and Hohmann, A. G. (2008). Cannabinoid CB2 Receptors: a Therapeutic Target for the Treatment of Inflammatory and Neuropathic Pain. Br. J. Pharmacol. 153, 319-334. doi:10.1038/sj.bjp.0707531

Guo, W., Wang, H., Watanabe, M., Shimizu, K., Zou, S., LaGraize, S. C., et al. (2007). Glial-cytokine-neuronal Interactions Underlying the Mechanisms of Persistent Pain. J. Neurosci. 27, 6006-6018. doi:10.1523/JNEUROSCI.017607.2007

Haney, M., Ward, A. S., Comer, S. D., Foltin, R. W., and Fischman, M. W. (1999). Abstinence Symptoms Following Smoked Marijuana in Humans. Psychopharmacology 141, 395-404. doi:10.1007/s002130050849

Henderson-Redmond, A. N., Nealon, C. M., Davis, B. J., Yuill, M. B., Sepulveda, D. E., Blanton, H. L., et al. (2020). c-Jun N Terminal Kinase Signaling Pathways Mediate Cannabinoid Tolerance in an Agonist-specific Manner. Neuropharmacology 164, 107847. doi:10.1016/j.neuropharm.2019.107847

Hernandez-Avila, C. A., Rounsaville, B. J., and Kranzler, H. R. (2004). Opioid-, Cannabis- and Alcohol-dependent Women Show More Rapid Progression to Substance Abuse Treatment. Drug Alcohol Depend. 74, 265-272. doi:10.1016/ j.drugalcdep.2004.02.001

Hsieh, G. C., Pai, M., Chandran, P., Hooker, B. A., Zhu, C. Z., Salyers, A. K., et al. (2011). Central and Peripheral Sites of Action for CB2 Receptor Mediated Analgesic Activity in Chronic Inflammatory and Neuropathic Pain Models in Rats. J. Pharmacol. 162, 428-440. doi:10.1111/j.1476-5381.2010.01046.x

Jin, W., Brown, S., Roche, J. P., Hsieh, C., Celver, J. P., Kovoor, A., et al. (1999). Distinct Domains of the CB1 Cannabinoid Receptor Mediate Desensitization and Internalization. J. Neurosci. 19, 3773-3780. doi:10.1523/jneurosci.19-1003773.1999

Jones, R. T., Benowitz, N. L., and Herning, R. I. (1981). Clinical Relevance of Cannabis Tolerance and Dependence. J. Clin. Pharmacol. 21, 143S-152S. doi:10.1002/j.1552-4604.1981.tb02589.x

Joseph, E. K., and Levine, J. D. (2003). Sexual Dimorphism for Protein Kinase Ce Signaling in a Rat Model of Vincristine-Induced Painful Peripheral Neuropathy. Neuroscience 119, 831-838. doi:10.1016/S0306-4522(03)00203-3

Khan, S. S., Secades-Villa, R., Okuda, M., Wang, S., Pérez-Fuentes, G., Kerridge, B. T., et al. (2013). Gender Differences in Cannabis Use Disorders: Results from the National Epidemiologic Survey of Alcohol and Related Conditions. Drug Alcohol Depend. 130, 101-108. doi:10.1016/j.drugalcdep.2012.10.015

Khasabova, I. A., Khasabov, S., Paz, J., Harding-Rose, C., Simone, D. A., and Seybold, V. S. (2012). Cannabinoid Type-1 Receptor Reduces Pain and
Neurotoxicity Produced by Chemotherapy. J. Neurosci. 32, 7091-7101. doi:10.1523/JNEUROSCI.0403-12.2012

King, K. M., Myers, A. M., Soroka-Monzo, A. J., Tuma, R. F., Tallarida, R. J., Walker, E. A., et al. (2017). Single and Combined Effects of $\Delta 9$-tetrahydrocannabinol and Cannabidiol in a Mouse Model of Chemotherapy-Induced Neuropathic Pain. $\mathrm{Br}$. J. Pharmacol. 174, 2832-2841. doi:10.1111/bph.13887

LaFleur, R. A., Wilson, R. P., Morgan, D. J., and Henderson-Redmond, A. N. (2018). Sex Differences in Antinociceptive Response to $\Delta-9$ tetrahydrocannabinol and $\mathrm{CP} 55,940$ in the Mouse Formalin Test. Neuroreport 29, 447-452. doi:10.1097/WNR.0000000000000993

Lynch, M. E., Cesar-Rittenberg, P., and Hohmann, A. G. (2014). A Double-Blind, Placebo-Controlled, Crossover Pilot Trial with Extension Using an Oral Mucosal Cannabinoid Extract for Treatment of Chemotherapy-Induced Neuropathic Pain. J. Pain Symptom Manage. 47, 166-173. doi:10.1016/ j.jpainsymman.2013.02.018

Lynch, M. E., and Ware, M. A. (2015). Cannabinoids for the Treatment of Chronic Non-Cancer Pain: An Updated Systematic Review of Randomized Controlled Trials. J. Neuroimmune Pharmacol. 10, 293-301. doi:10.1007/s11481-0159600-6

Martin, B. R., Sim-Selley, L. J., and Selley, D. E. (2004). Signaling Pathways Involved in the Development of Cannabinoid Tolerance. Trends Pharmacol. Sci. 25, 325-330. doi:10.1016/j.tips.2004.04.005

Marusich, J. A., Craft, R. M., Lefever, T. W., and Wiley, J. L. (2015). The Impact of Gonadal Hormones on Cannabinoid Dependence. Exp. Clin. Psychopharmacol. 23, 206-216. doi:10.1037/pha0000027

Matsuda, L. A., Lolait, S. J., Brownstein, M. J., Young, A. C., and Bonner, T. I. (1990). Structure of a Cannabinoid Receptor and Functional Expression of the Cloned cDNA. Nature 346, 561-564. doi:10.1038/346561a0

Milligan, E. D., O'Connor, K. A., Nguyen, K. T., Armstrong, C. B., Twining, C., Gaykema, R. P. A., et al. (2001). Intrathecal HIV-1 Envelope Glycoprotein Gp120 Induces Enhanced Pain States Mediated by Spinal Cord Proinflammatory Cytokines. J. Neurosci. 21, 2808-2819. doi:10.1523/ jneurosci.21-08-02808.2001

Milligan, E. D., Twining, C., Chacur, M., Biedenkapp, J., O'Connor, K., Poole, S., et al. (2003). Spinal Glia and Proinflammatory Cytokines Mediate MirrorImage Neuropathic Pain in Rats. J. Neurosci. 23, 1026-1040. doi:10.1523/ jneurosci.23-03-01026.2003

Mogil, J. S. (2012). Sex Differences in Pain and Pain Inhibition: Multiple Explanations of a Controversial Phenomenon. Nat. Rev. Neurosci. 13, 859-866. doi:10.1038/nrn3360

Morgan, D. J., Davis, B. J., Kearn, C. S., Marcus, D., Cook, A. J., Wager-Miller, J., et al. (2014). Mutation of Putative GRK Phosphorylation Sites in the Cannabinoid Receptor 1 (CB1R) Confers Resistance to Cannabinoid Tolerance and Hypersensitivity to Cannabinoids in Mice. J. Neurosci. 34, 5152-5163. doi:10.1523/JNEUROSCI.3445-12.2014

Munro, S., Thomas, K. L., and Abu-Shaar, M. (1993). Molecular Characterization of a Peripheral Receptor for Cannabinoids. Nature 365, 61-65. doi:10.1038/ $365061 \mathrm{a} 0$

Nealon, C. M., Henderson-Redmond, A. N., Hale, D. E., and Morgan, D. J. (2019). Tolerance to WIN55,212-2 Is Delayed in Desensitization-Resistant S426A/ S430A Mice. Neuropharmacology 148, 151-159. doi:10.1016/ J.NEUROPHARM.2018.12.026

Nguyen, P. T., Schmid, C. L., Raehal, K. M., Selley, D. E., Bohn, L. M., and SimSelley, L. J. (2012). $\beta$-Arrestin2 Regulates Cannabinoid CB1 Receptor Signaling and Adaptation in a Central Nervous System Region-Dependent Manner. Biol. Psychiatry 71, 714-724. doi:10.1016/j.biopsych.2011.11.027

Pertwee, R. G. (1997). Pharmacology of Cannabinoid CB1 and CB2 Receptors. Pharmacol. Ther. 74, 129-180. doi:10.1016/S0163-7258(97)82001-3

Pini, L. A., Guerzoni, S., Cainazzo, M. M., Ferrari, A., Sarchielli, P., Tiraferri, I., et al. (2012). Nabilone for the Treatment of Medication Overuse Headache: Results of a Preliminary Double-Blind, Active-Controlled, Randomized Trial. J. Headache Pain 13, 677-684. doi:10.1007/s10194012-0490-1

Rahn, E. J., Makriyannis, A., and Hohmann, A. G. (2009). Activation of Cannabinoid CB1 and CB2 Receptors Suppresses Neuropathic Nociception Evoked by the Chemotherapeutic Agent Vincristine in Rats. Br. J. Pharmacol. 152, 765-777. doi:10.1038/sj.bjp.0707333 
Rinaldi-Carmona, M., Barth, F., Millan, J., Derocq, J. M., Casellas, P., Congy, C., et al. (1998). SR 144528, the First Potent and Selective Antagonist of the CB2 Cannabinoid Receptor. J. Pharmacol. Exp. Ther. 284, 644-650.

Rinaldi-Carmona, M., Barth, F., Héaulme, M., Shire, D., Calandra, B., Congy, C., et al. (1994). SR141716A, a Potent and Selective Antagonist of the Brain Cannabinoid Receptor. FEBS Lett. 350, 240-244. doi:10.1016/0014-5793(94) 00773-X

Roelofs, R. I., Hrushesky, W., Rogin, J., and Rosenberg, L. (1984). Peripheral Sensory Neuropathy and Cisplatin Chemotherapy. Neurology 34, 934. doi:10.1212/wnl.34.7.934

Rosen, S., Ham, B., and Mogil, J. S. (2017). Sex Differences in Neuroimmunity and Pain. J. Neurosci. Res. 95, 500-508. doi:10.1002/jnr.23831

Schertzinger, M., Wesson-Sides, K., Parkitny, L., and Younger, J. (2018). Daily Fluctuations of Progesterone and Testosterone Are Associated With Fibromyalgia Pain Severity. J. Pain 19, 410-417. doi:10.1016/j.jpain.2017.11.013

Selley, D. E., Cassidy, M. P., Martin, B. R., and Sim-Selley, L. J. (2004). Long-Term Administration of $\Delta 9$-Tetrahydrocannabinol Desensitizes CB1-, Adenosine A1-, and GABAB-Mediated Inhibition of Adenylyl Cyclase in Mouse Cerebellum. Mol. Pharmacol. 66, 1275-1284. doi:10.1124/mol.104.000604

Sim, L. J., Hampson, R. E., Deadwyler, S. A., and Childers, S. R. (1996). Effects of Chronic Treatment with 49 -Tetrahydrocannabinol on CannabinoidStimulated [35S]GTP $\gamma$ S Autoradiography in Rat Brain. J. Neurosci. 16, 8057-8066. doi:10.1523/jneurosci.16-24-08057.1996

Starowicz, K., Makuch, W., Osikowicz, M., Piscitelli, F., Petrosino, S., Di Marzo, V., et al. (2012). Spinal Anandamide Produces Analgesia in Neuropathic Rats: Possible CB1- and TRPV1-Mediated Mechanisms. Neuropharmacology 62, 1746-1755. doi:10.1016/j.neuropharm.2011.11.021

Toth, C. C., Jedrzejewski, N. M., Ellis, C. L., and Frey, W. H. (2010). Cannabinoidmediated Modulation of Neuropathic Pain and Microglial Accumulation in a Model of Murine Type I Diabetic Peripheral Neuropathic Pain. Mol. Pain 6, 1744-8069. doi:10.1186/1744-8069-6-16

Toth, C., Mawani, S., Brady, S., Chan, C., Liu, C., Mehina, E., et al. (2012). An Enriched-Enrolment, Randomized Withdrawal, Flexible-Dose, Double-Blind, Placebo-Controlled, Parallel Assignment Efficacy Study of Nabilone as Adjuvant in the Treatment of Diabetic Peripheral Neuropathic Pain. Pain 153, 2073-2082. doi:10.1016/j.pain.2012.06.024

Tseng, A. H., and Craft, R. M. (2001). Sex Differences in Antinociceptive and Motoric Effects of Cannabinoids. Eur. J. Pharmacol. 430, 41-47. doi:10.1016/ S0014-2999(01)01267-5

Turcotte, D., Doupe, M., Torabi, M., Gomori, A., Ethans, K., Esfahani, F., et al. (2015). Nabilone as an Adjunctive to Gabapentin for Multiple SclerosisInduced Neuropathic Pain: A Randomized Controlled Trial. Pain Med. 16, 149-159. doi:10.1111/pme.12569

Van Der Hoop, R. G., Van Der Burg, M. E. L., Ten Huinink, W. W. B., Van Houwelingen, J. C., and Neijt, J. P. (1990). Incidence of Neuropathy in 395 Patients with Ovarian Cancer Treated with or without Cisplatin. Cancer 66, 1697-1702. doi:10.1002/1097-0142(19901015)66:8<1697::aid-cncr2820660808>3.0.co;2-g

Vera, G., Cabezos, P. A., Martín, M. I., and Abalo, R. (2013). Characterization of Cannabinoid-Induced Relief of Neuropathic Pain in a Rat Model of CisplatinInduced Neuropathy. Pharmacol. Biochem. Behav. 105, 205-212. doi:10.1016/ j.pbb.2013.02.008

Wakley, A. A., and Craft, R. M. (2011). Antinociception and Sedation Following Intracerebroventricular Administration of $\Delta 9$ - tetrahydrocannabinol in Female vs. Male Rats. Behav. Brain Res. 216, 200-206. doi:10.1016/j.bbr.2010.07.037

Wakley, A. A., McBride, A. A., Vaughn, L. K., and Craft, R. M. (2014a). Cyclic Ovarian Hormone Modulation of Supraspinal $\Delta 9$-tetrahydrocannabinolinduced Antinociception and Cannabinoid Receptor Binding in the Female Rat. Pharmacol. Biochem. Behav. 124, 269-277. doi:10.1016/J.PBB.2014.06.007

Wakley, A. A., Wiley, J. L., and Craft, R. M. (2015). Gonadal Hormones Do Not Alter the Development of Antinociceptive Tolerance to delta-9tetrahydrocannabinol in Adult Rats. Pharmacol. Biochem. Behav. 133, 111-121. doi:10.1016/J.PBB.2015.03.021

Wakley, A. A., Wiley, J. L., and Craft, R. M. (2014b). Sex Differences in Antinociceptive Tolerance to delta-9-tetrahydrocannabinol in the Rat. Drug and Alcohol Dependence 143, 22-28. doi:10.1016/j.drugalcdep.2014.07.029

Walker, M. J., Michael, J. W., Strangman, N. M., and Huang, S. M. (2001). Cannabinoids and Pain. Pain Res. Manage. 6, 413641. doi:10.1155/2001/413641

Watkins, L. R., Milligan, E. D., and Maier, S. F. (2001). Glial Activation: A Driving Force for Pathological Pain. Trends Neurosciences 24, 450-455. doi:10.1016/ S0166-2236(00)01854-3

Wiley, J. L., Barrus, D. G., Farquhar, C. E., Lefever, T. W., and Gamage, T. F. (2021). Sex, Species and Age: Effects of Rodent Demographics on the Pharmacology of $\Delta$ 9-tetrahydrocanabinol. Prog. Neuro-Psychopharmacology Biol. Psychiatry 106, 110064. doi:10.1016/j.pnpbp.2020.110064

Wilsey, B., Marcotte, T., Deutsch, R., Gouaux, B., Sakai, S., and Donaghe, H. (2013). Low-Dose Vaporized Cannabis Significantly Improves Neuropathic Pain. J. Pain 14, 136-148. doi:10.1016/J.JPAIN.2012.10.009

Wong, S. S. C., Chan, W. S., and Cheung, C. W. (2020). Analgesic Effects of Cannabinoids for Chronic Non-cancer Pain: a Systematic Review and MetaAnalysis with Meta-Regression. J. Neuroimmune Pharmacol. 15, 801-829. doi:10.1007/s11481-020-09905-y

Wotherspoon, G., Fox, A., McIntyre, P., Colley, S., Bevan, S., and Winter, J. (2005). Peripheral Nerve Injury Induces Cannabinoid Receptor 2 Protein Expression in Rat Sensory Neurons. Neuroscience 135, 235-245. doi:10.1016/ j.neuroscience.2005.06.009

Yuill, M. B., Hale, D. E., Guindon, J., and Morgan, D. J. (2017). Anti-nociceptive Interactions between Opioids and a Cannabinoid Receptor 2 Agonist in Inflammatory Pain. Mol. Pain 13, 1744806917728227. doi:10.1177/ 1744806917728227

Zhang, J., Hoffert, C., Vu, H. K., Groblewski, T., Ahmad, S., and O'Donnell, D. (2003). Induction of CB2 Receptor Expression in the Rat Spinal Cord of Neuropathic but Not Inflammatory Chronic Pain Models. Eur. J. Neurosci. 17, 2750-2754. doi:10.1046/j.1460-9568.2003.02704.x

Conflict of Interest: The authors declare that the research was conducted in the absence of any commercial or financial relationships that could be construed as a potential conflict of interest.

Copyright $\odot 2021$ Henderson-Redmond, Crawford, Sepulveda, Hale, Lesperance and Morgan. This is an open-access article distributed under the terms of the Creative Commons Attribution License (CC BY). The use, distribution or reproduction in other forums is permitted, provided the original author(s) and the copyright owner $(s)$ are credited and that the original publication in this journal is cited, in accordance with accepted academic practice. No use, distribution or reproduction is permitted which does not comply with these terms. 